\title{
Feasibility Study for a Subcritical Assembly at the Oak Ridge National Laboratory
}

Approved for public release. Distribution is unlimited.
Douglas Bowen Andrew Holcomb Shane Hart

August 2020 


\title{
DOCUMENT AVAILABILITY
}

Reports produced after January 1, 1996, are generally available free via US Department of Energy (DOE) SciTech Connect.

Website www.osti.gov

Reports produced before January 1, 1996, may be purchased by members of the public from the following source:

\author{
National Technical Information Service \\ 5285 Port Royal Road \\ Springfield, VA 22161 \\ Telephone 703-605-6000 (1-800-553-6847) \\ TDD 703-487-4639 \\ Fax 703-605-6900 \\ E-mail info@ntis.gov \\ Website http://classic.ntis.gov/
}

Reports are available to DOE employees, DOE contractors, Energy Technology Data Exchange representatives, and International Nuclear Information System representatives from the following source:

Office of Scientific and Technical Information

PO Box 62

Oak Ridge, TN 37831

Telephone 865-576-8401

Fax 865-576-5728

E-mail reports@osti.gov

Website http://www.osti.gov/contact.html

This report was prepared as an account of work sponsored by an agency of the United States Government. Neither the United States Government nor any agency thereof, nor any of their employees, makes any warranty, express or implied, or assumes any legal liability or responsibility for the accuracy, completeness, or usefulness of any information, apparatus, product, or process disclosed, or represents that its use would not infringe privately owned rights. Reference herein to any specific commercial product, process, or service by trade name, trademark, manufacturer, or otherwise, does not necessarily constitute or imply its endorsement, recommendation, or favoring by the United States Government or any agency thereof. The views and opinions of authors expressed herein do not necessarily state or reflect those of the United States Government or any agency thereof. 
Reactor and Nuclear Systems Division

and

DOE/NNSA Nuclear Criticality Safety Program

FEASIBILITY STUDY FOR THE DESIGN AND EXECUTION OF A CRITICAL/SUBCRITICAL ASSEMBLY AT THE OAK RIDGE NATIONAL LABORATORY

Douglas Bowen

Andrew Holcomb

Shane Hart

Date Published:

August 2020

Prepared by

OAK RIDGE NATIONAL LABORATORY

Oak Ridge, TN 37831-6283

managed by

UT-BATTELLE, LLC

for the

US DEPARTMENT OF ENERGY

under contract DE-AC05-00OR22725 


\section{CONTENTS}

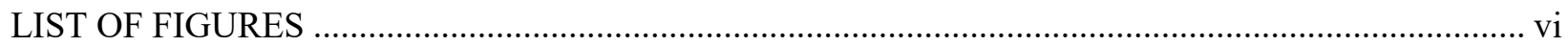

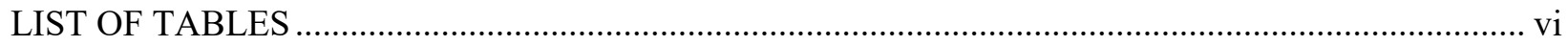

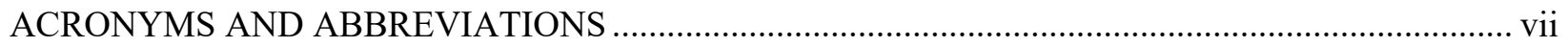

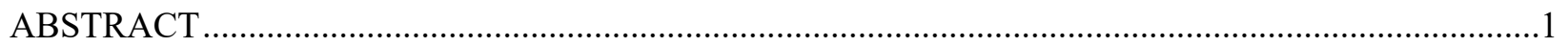

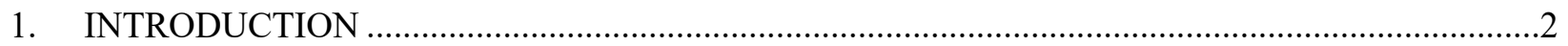

1.1 CRITICAL AND SUBCRITICAL ASSEMBLIES IN THE UNITED STATES ....................2

1.1.1 NCSP Nuclear Criticality Safety Training and Education Program .............................

1.1.2 Backup Capability to Conduct Hands-On Training and Experiments ............................5

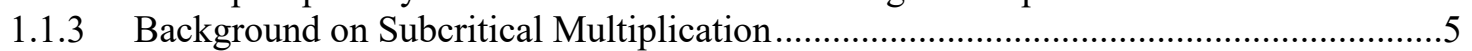

1.1.4 Approach to the Multiplication Limit Using the Inverse of the Multiplication..............6

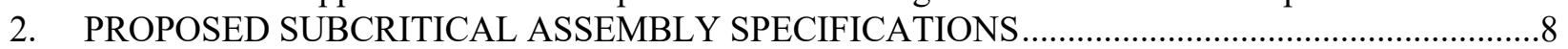

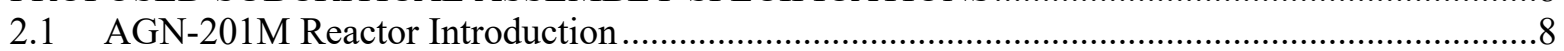

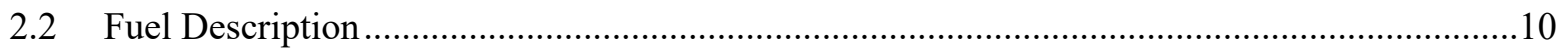

2.3 Neutron Reflectors for the Subcritical Assembly ...............................................................13

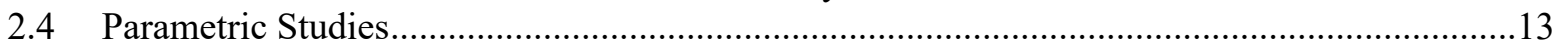

2.4.1 Core \& Reflector Parametric Study .....................................................................13

2.4.2 Subcritical Assembly: Effect of Fissile Mass and Neutron Reflection.........................16

2.4.3 Subcritical Assembly Approach-to-Multiplication Limit Parametric

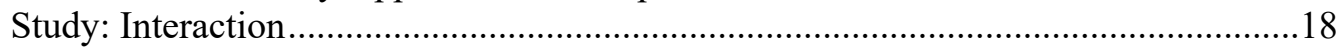

2.4.4 Subcritical Assembly Void Replacement Study: Moderation .....................................20

2.4.5 Subcritical Assembly Approach-to-Multiplication Limit Parametric Study:

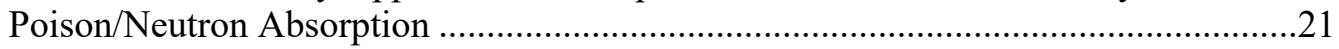

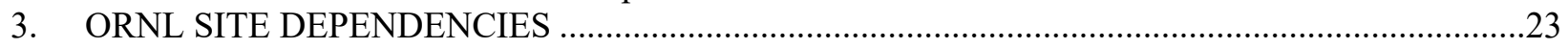

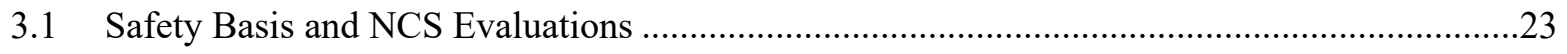

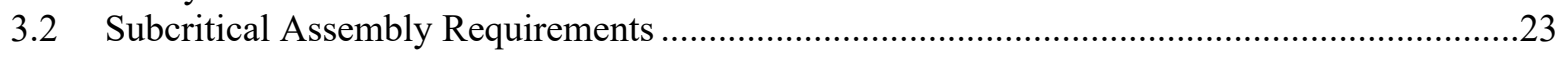

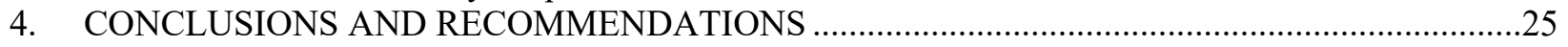

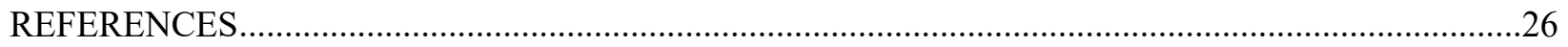




\section{LIST OF FIGURES}

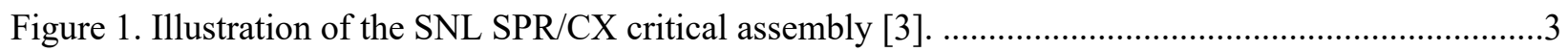

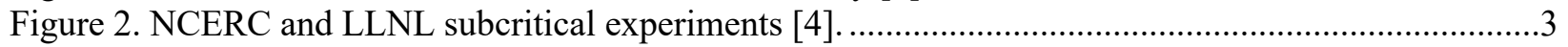

Figure 3. NCERC approach-to-critical, delayed critical, and supercritical experiments [4]......................4

Figure 4. Plot of 1/M vs. mass for an approach-to-critical experiment. ....................................................6

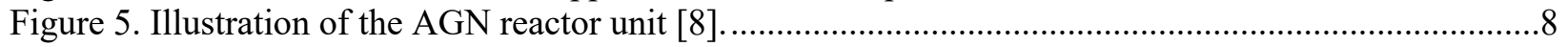

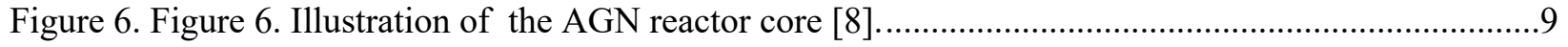

Figure 7. AGN-201M core showing fuel plate details [10] ................................................................10

Figure 8. AGN-201M core with core control holes empty and filled......................................................14

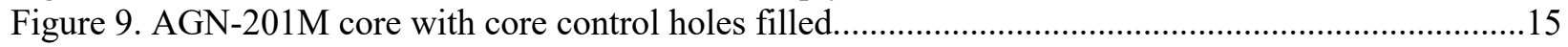

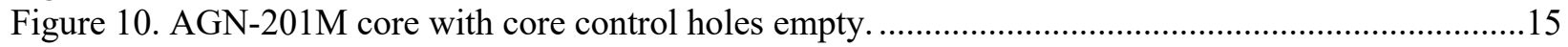

Figure 11. Graphite reflector core multiplication KENO VI results.....................................................16

Figure 12. Mean KENO VI $k_{\text {eff }}$ results: fissile mass approach-to-multiplication limit..............................18

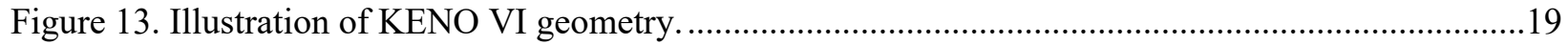

Figure 14. Mean KENO VI $k_{e f f}$ results: interaction parametric study....................................................19

Figure 15. ORSA control rod hole map $(1$ - CR; 2 \& 4 - SR1 \& SR2; 3 - FCR) ....................................20

\section{LIST OF TABLES}

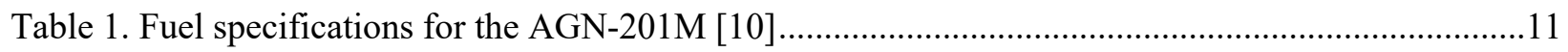

Table 2. Attributes of the AGN-201M upper fuel plates [10] .............................................................11

Table 3. Attributes of the AGN-201M lower fuel plates [10] ................................................................11

Table 4. AGN-201M research reactor fuel and components for the ORSA …........................................12

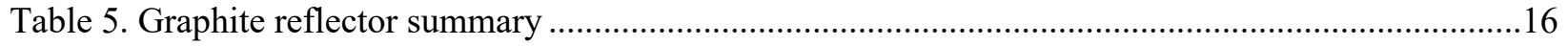

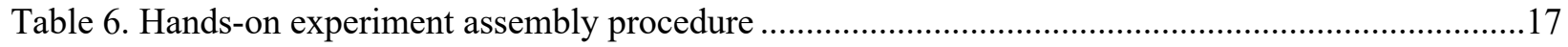

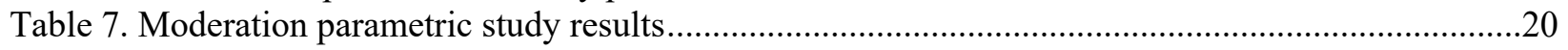

Table 8. Neutron absorber (poison) parametric study results ..............................................................21 


\section{ACRONYMS AND ABBREVIATIONS}

$\begin{array}{ll}\text { ANS } & \text { American National Standard } \\ \text { ANSI } & \text { American National Standards Institute } \\ \text { BeRP } & \text { beryllium-reflected plutonium } \\ \text { CCR } & \text { coarse control rod } \\ \text { CSO } & \text { criticality safety officer } \\ \text { DAF } & \text { Device Assembly Facility } \\ \text { DOE } & \text { US Department of Energy } \\ \text { FCR } & \text { fine control rod } \\ \text { FMH } & \text { fissile material handler } \\ \text { FY } & \text { fiscal year } \\ \text { HALEU } & \text { high-assay low enriched uranium } \\ \text { HDPE } & \text { high density polyethylene } \\ \text { HEU } & \text { highly enriched uranium } \\ \text { HFIR } & \text { High Flux Isotope Reactor } \\ \text { HO } & \text { hands on } \\ \text { ICSBEP } & \text { International Critical Benchmark Experiments Project } \\ \text { ISU } & \text { Idaho State University } \\ \text { LANL } & \text { Los Alamos National Laboratory } \\ \text { LEU } & \text { low-enriched uranium } \\ \text { LLNL } & \text { Lawrence Livermore National Laboratory } \\ \text { MC\&A } & \text { Material Control and Accountability } \\ \text { MGR } & \text { manager } \\ \text { NCERC } & \text { National Criticality Experiments Research Center } \\ \text { NCS } & \text { nuclear criticality safety } \\ \text { NCSP } & \text { Nuclear Criticality Safety Program } \\ \text { NNSA } & \text { National Nuclear Security Administration } \\ \text { NNSS } & \text { Nevada National Security Site } \\ \text { ORNL } & \text { Oak Ridge National Laboratory } \\ \text { ORSA } & \text { ORNL Subcritical Assembly } \\ \text { SNL } & \text { Sandia National Laboratories } \\ \text { SNM } & \text { special nuclear material } \\ \text { SPR/CX } & \text { Sandia Pulse Reactor/Critical Experiments } \\ \text { SR } & \text { safety rod } \\ \text { TACS } & \text { Training Assembly for Criticality Safety } \\ \text { T\&E } & \text { Training and Education } \\ \text { UNM } & \text { University of New Mexico } \\ \text { UT } & \text { University of Tennessee } \\ & \end{array}$




\begin{abstract}
A conceptual design has been completed for a new subcritical assembly at Oak Ridge National Laboratory (ORNL). This subcritical assembly will support the Nuclear Criticality Safety Program (NCSP) training and education program to augment current subcritical assembly capabilities at Sandia National Laboratories (SNL) and at the National Criticality Experiments Research Center (NCERC). The proposed subcritical assembly uses legacy AGN-201M research reactor fuel plates that are available at the Y-12 National Security Complex. This subcritical assembly contains approximately 620 grams of ${ }^{235} \mathrm{U}$ as $\mathrm{UO}_{2}$ particulates distributed homogeneously in radiation-stabilized polyethylene. The fuel plates will have a graphite neutron reflector to obtain a core multiplication, $M$, from 10 to 50 , corresponding to a $k_{\text {eff }}$ of 0.9 to 0.95 , respectively. The subcritical assembly will be able to support at least four experiments for the training courses: (1) the addition of fissile material to increase neutron multiplication (mass), (2) a core separation experiment (interaction), (3) the effect of adding moderators to the core (moderation), and (4) the effect of adding neutron absorbers to the core (poison/absorption). The proposed ORNL subcritical assembly will provide additional student bandwidth to support NCSP training courses and to provide for some backup capacity in the event that nuclear facility operations are disrupted at SNL or NCERC due to some unforeseen issue. The subcritical assembly will be designed to be an inherently safe subcritical assembly-subcritical under all normal and abnormal conditions - and it will provide the capability to conduct hands-on training to support NCSP and general nuclear criticality safety (NCS) staff training and qualification goals.
\end{abstract}




\section{INTRODUCTION}

Nuclear criticality safety (NCS) is the field involved with protecting personnel who are processing, handling, storing, and transporting fissionable material. Fissionable material can become unsafe under some circumstances and configurations, producing a neutron chain reaction that can result in a burst of radiation that can be dangerous to nearby personnel. Operations staff that work in these environments must take NCS training, including instruction in hands-on operations with fissionable materials, to ensure that all workers are aware of the risks involved with these types of operations. Training assemblies are used in these efforts to provide adequate, safe training that meets regulatory and consensus standard requirements. There are two types of these training assemblies: critical and subcritical assemblies. Critical assemblies involve hands-on operations that can be used until safety limits are reached. At this stage, remote operations are implemented until a critical configuration is achieved. The critical point, also known as delayed critical, is the point at which a neutron balance has been achieved with neutron leakage, neutron absorption (parasitic capture and fission production), and neutron scattering (reflection). Delayed critical is the sensitive window during which a critical assembly is dependent on both delayed and prompt neutrons instead of prompt neutrons alone. The radiation or power level can be low (zero) or raised to a higher level by increasing the neutron population. Critical assemblies, which are also known as burst assemblies, have a configuration with sufficient reactivity to achieve a prompt critical burst that resembles a criticality accident in a process facility. Subcritical assemblies are strictly designed to be safe under all normal and credible abnormal conditions [1] for approach-to-critical experiments until the allowed neutron multiplication is achieved. These assemblies are discussed further in Section 1.1. These assemblies are very useful for demonstrating the principles of NCS in a safe training environment.

\subsection{CRITICAL AND SUBCRITICAL ASSEMBLIES IN THE UNITED STATES}

In the United States there are currently two nuclear facilities at which critical assemblies are operated to support NCS hands-on training. These facilities are operated by the US Department of Energy (DOE)/National Nuclear Security Administration (NNSA). NCS training is conducted by the DOE/NNSA Nuclear Criticality Safety Program (NCSP) training and education programs.

The Sandia Pulse Reactor/Critical Experiments (SPR/CX) critical facility at Sandia National Laboratory (SNL) performs critical measurements for training and for the generation of high-quality benchmark critical experiments for the International Critical Safety Benchmark Experiments Project (ICSBEP) handbook. This facility utilizes low-enriched light water reactor fuel pins loaded into a grid plate and filled with water to perform approach-to-critical and delayed critical measurements (Figure 1). Typically, four hands-on experiments are conducted for NCS training courses to train students on the principles of reactor physics and NCS: (1) the approach-to-critical experiment on fuel loading (examining the effect of adding fissile mass), (2) the approach-to-critical experiment on moderator level (examining the effect of adding moderator), (3) the demonstration on the effect of removing interior fuel rods from the fuel array (examining the effect of increasing reactivity by removing fissile mass and adding moderation), and (4) the approach-to-critical experiment on the spacing of two fuel arrays (examining the effect of increasing neutron interaction between core halves) [2]. Hands-on training at SNL can be attended by students with and without security clearances, including foreign nationals. 


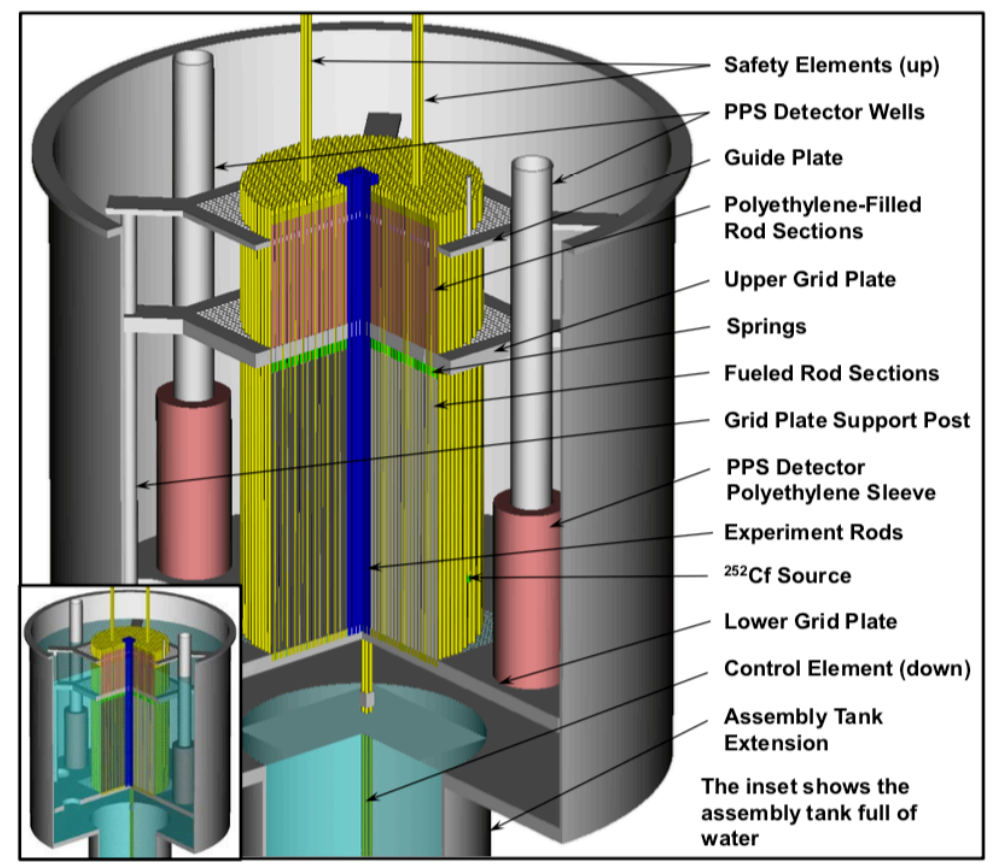

Figure 1. Illustration of the SNL SPR/CX critical assembly [3].

The second nuclear facility that conducts subcritical and critical experiments is located at the Nevada National Security Site (NNSS) in the Device Assembly Facility (DAF). The facility used in the DAF for hands-on training is the National Criticality Experiments Research Center (NCERC), which contains a special nuclear material (SNM) vault, a high bay for subcritical and other experiments, and four critical assemblies: the Godiva IV fast burst assembly for prompt supercritical experiments, Flattop for critical and delayed critical experiments, Planet for approach-to-critical and delayed critical experiments, and the Comet vertical split-table assemblies. All assemblies except Comet are used for NCS training. Also, a subcritical demonstration is performed at NCERC involving the beryllium-reflected plutonium (BeRP) ball (4.5 $\mathrm{kg} \alpha$-phase $\mathrm{Pu})$ and Neptunium sphere $\left(6 \mathrm{~kg}{ }^{237} \mathrm{~Np}\right)$. A large variety of experiments can be conducted at NCERC, which is currently operated by Los Alamos National Laboratory (LANL) for the NCSP. Lawrence Livermore National Laboratory (LLNL) currently operates a subcritical training assembly known as the Training Assembly for Criticality Safety (TACS) to support NCSP training. Figures 2 and 3 summarize the NCERC/DAF experiments used to conduct the NCSP hands-on training courses.

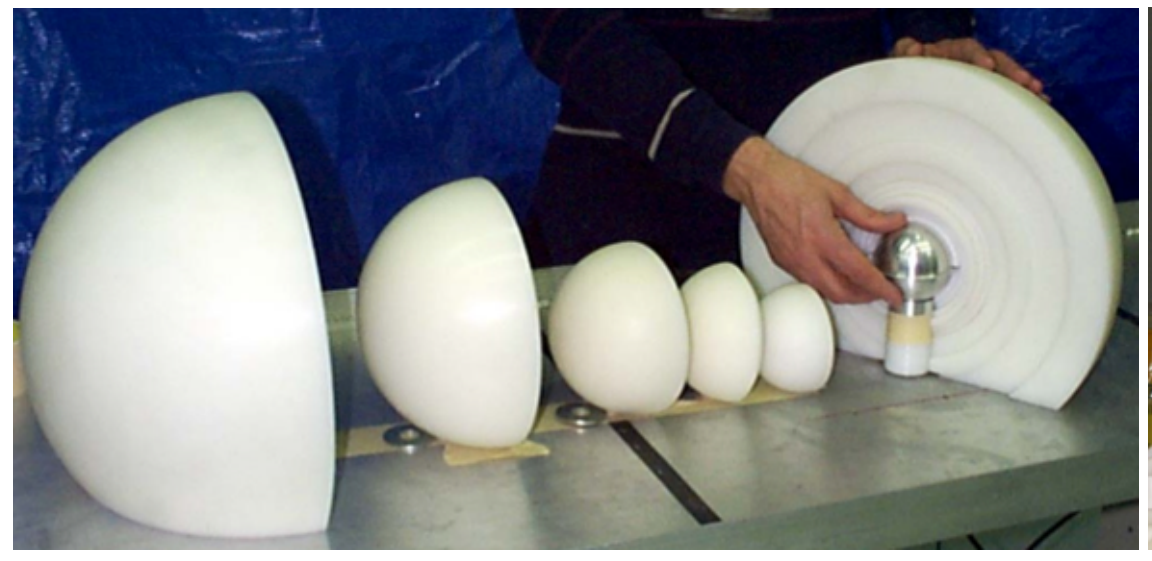

NCERC BeRP ball and ${ }^{237} \mathrm{~Np}$ sphere subcritical demonstration

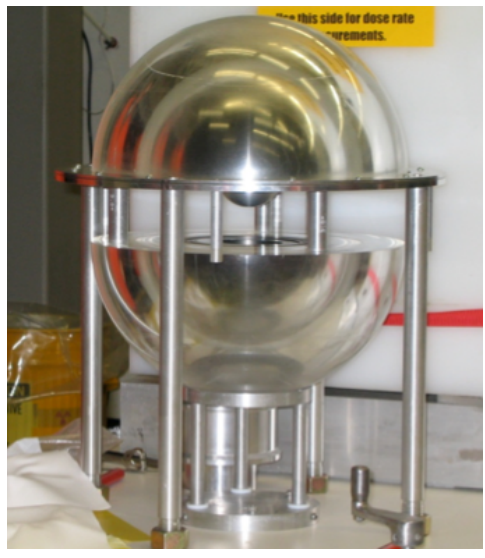

LLNL training assembly for criticality safety (TACS)

Figure 2. NCERC and LLNL subcritical experiments [4]. 


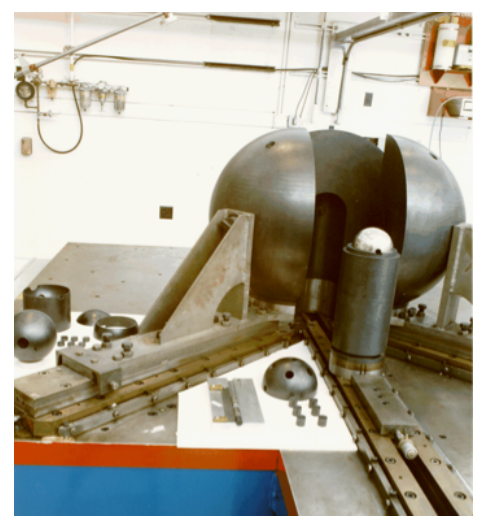

Flattop critical assembly: delayed critical and delayed supercritical free run subcritical demonstration

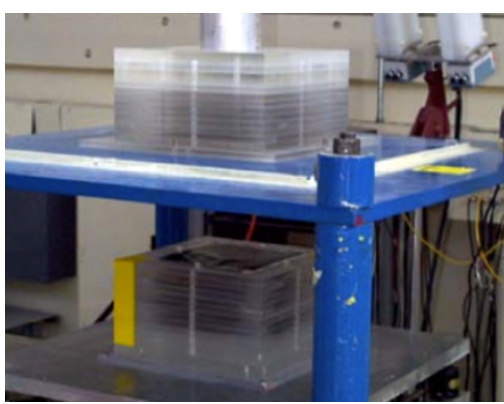

Planet vertical split table: HEU foil handstack approach-to-critical and delayed critical experiment

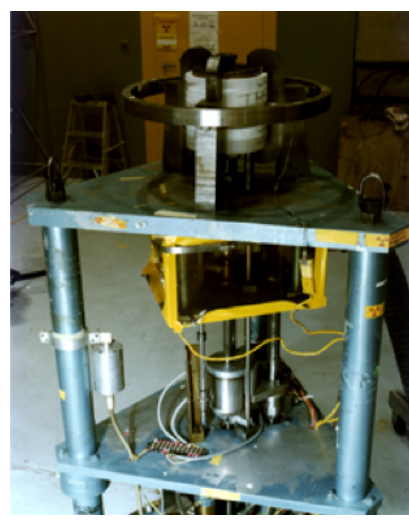

Godiva IV burst assembly: delayed critical and prompt supercritical experiment

Figure 3. NCERC approach-to-critical, delayed critical, and supercritical experiments [4].

NCSP currently funds the SNL and NCERC facilities to perform NCS hands-on training and critical experiments for students from domestic and international NCS communities. Operations in these nuclear facilities can be paused or delayed due to the complexities of operating them. For example, safety basis issues, criticality safety infractions, fires, electrical issues, etc., could impact the NCS training courses and normal nuclear facility operations. Because the NCSP NCS training program is important for NCS engineering training and qualification programs in the United States [5], NCERC, DAF, and SNL nuclear facility issues can significantly delay student qualification progress. The purpose of this work is to propose an alternative training location for the eastern United States as a backup venue in the event of $\mathrm{DAF} /$ Sandia nuclear facility issues, as they arise, and also to provide additional NCS training bandwidth.

\subsubsection{NCSP Nuclear Criticality Safety Training and Education Program}

The NCSP training program began with hands-on operations at LANL until 2004, when TA-18 (Pajarito Site) was closed, and the critical assemblies, fuel, and other operations, were relocated to DAF. Hands-on training operations at DAF were restarted in 2011 with the NCERC subcritical and critical assemblies and the LLNL TACs subcritical assembly. Until NCERC operations were restarted at DAF, LLNL performed the hands-on training for the NCSP at LLNL using the TACs subcritical assembly. After DAF/NCERC operations were restarted, TACs operations were continued for the revised NCSP Training and Education (T\&E) program [5].

The NCSP T\&E program [5] consists of two training courses: (1) 2-Week Hands-On Training for NCS Engineers (HO Course), and (2) 1-Week Managers/Criticality Safety Officer (CSO) Training (MGR Course). The 2-week HO Course includes one week of lecture at the Nevada Field Office or the National Atomic Testing Museum, and one week of hands-on training at SNL or NCERC. Students with DOE "Q" clearances can attend the NCERC hands-on training, and students with DOE "L" or "Q" clearances or those who are uncleared or are foreign nationals can attend the SNL hands-on training.

Approximately 60-70 students attend the NCSP training courses each year, and about 500 NCS students have attended the training since 2011. Additional courses can be added as needed to accommodate the training needs for the NCS community. For example, a special, hands on (HO) Course for the Y-12 
Nuclear Security Complex (Y-12) has been scheduled in Fiscal Year (FY) 2021 to accommodate an influx of new hires going through the Y-12 training and qualification process.

\subsubsection{Backup Capability to Conduct Hands-On Training and Experiments}

Since 2011, multiple events at NCERC and SNL have impacted or have had the potential to impact NCSP T\&E courses. NCERC and SNL have essentially provided backup capability for each other. However, using NCERC as a backup for SNL presents an issue because most of the students are either uncleared or possess a DOE "L" clearance, so they cannot access the DAF to attend the training. In these cases, the NCSP management team must reschedule the course, which results in student backlog. Appendix A provides the NCSP proposals for FY 2019 and FY 2021 to provide backup capability for the NCERC and SNL HO courses. A new subcritical assembly is proposed for the Oak Ridge National Laboratory (ORNL) to enhance the NCSP T\&E Program by providing a backup capability for the SNL and/or NCERC facilities as needed due to nuclear facility issues that could impact course availability. An ORNL subcritical assembly (ORSA) would make the training available for those who typically cannot attend the NCSP T\&E courses: fissile material handlers, process operators, nuclear engineering students, summer interns, etc. A large target audience could take advantage of this capability at ORNL, approximately 100-200 students per year.

\subsubsection{Background on Subcritical Multiplication}

The ORSA will use a ${ }^{252} \mathrm{Cf}$ source and ${ }^{3} \mathrm{He}$ detectors to measure the neutrons that leak from the assembly during hands-on experiments. A neutron source serves as the reference source of neutrons for comparison with the fissile core multiplication, which is proportional to the number of neutrons that leak from the core. For these measurements, the detector location must remain unchanged so that its solid angle, efficiency, etc., can be disregarded during the procedure. This setup allows for comparison of the difference between successive changes in the assembly configuration during the experiment resulting in a change in the core reactivity, as indicated by a change in the neutron multiplication. Neutron multiplication, $M$, is the ratio of the number of neutrons in the assembly due to the presence of the ${ }^{252} \mathrm{Cf}$ source with the fissionable material to the number of neutrons from the ${ }^{252} \mathrm{Cf}$ source alone per unit time. Core multiplication, $M$, is defined in Eq. (1) [6],

$$
M=\frac{v F+S}{S}
$$

where $v$ is the average number of neutrons emitted per fission event (nubar), $F$ is the fission rate in the assembly, and $S$ is the rate at which source neutrons $\left({ }^{252} \mathrm{Cf}\right.$ source) enter the assembly. Due to the fissions in the uranium in the core, the assembly amplifies or multiplies the number of neutrons in the system. In other words, $M=10$ indicates that if a single source neutron enters the subcritical assembly, then 10 neutrons are created inside the core due to uranium fission. The system effective multiplication factor, $k_{\text {eff }}$, can be related to core multiplication. First, the $k_{\text {eff }}$ is defined as the ratio of the number of neutrons in the current generation to the number of neutrons in the preceding generation, as shown in Eq. (2):

$$
k_{e f f}=\frac{\text { Number of neutrons in the current generation }}{\text { Number of neutrons in the preceding generation }} .
$$

As presented in Percher's "Module 2: Introduction to Critical Experiment Methods" [6], the source neutrons will generate $\mathrm{S} \cdot \boldsymbol{k}_{\text {eff }}$ first generation neutrons, which will then generate $\mathrm{S} \cdot \boldsymbol{k}_{\text {eff }}^{2}$ in the second generation, and so forth. This is shown in Eq. (3), 


$$
M=\frac{S\left(1+k_{e f f}+k_{e f f^{2}}+k_{\left.e f f^{3}+\ldots\right)}\right.}{S}
$$

which can be simplified by knowing that, for values less than 1 , the series converges to a simple relationship independent of the ${ }^{252} \mathrm{Cf}$ source that is present, as shown in Eq. (4):

$$
M=\frac{S\left(1+k_{e f f}+k_{\left.e f f^{2}+k_{e f f}{ }^{3}+\ldots\right)}\right.}{S} \approx \frac{1}{1-k_{e f f}} .
$$

Thus, this parametric study can be performed by calculating the $k_{\text {eff }}$ for an ORSA configuration, which can then be related to core multiplication. In reality, however, neutron counters are used to obtain neutron counts after fuel/reflector additions to the core. The neutron counts are used to calculate the neutron multiplication, which can then be used to approximate neutron multiplication.

\subsubsection{Approach to the Multiplication Limit Using the Inverse of the Multiplication}

The hands-on training will involve adding reactivity by increasing core mass and neutron reflector material to the OCA until the core multiplication limit is reached. This experiment considers a systematic change to a single parameter (mass, reflection, spacing/interaction, etc.) of interest in the experiment. The resulting measured core multiplication will approach an infinite value at the critical state. The inverse multiplication $(1 / M)$ is calculated based on counting data and is plotted to estimate the critical parameter of interest. Figure 4 illustrates this process, which provides direct insight into how the hands-on operations will result in a critical assembly. However, since the ORSA cannot achieve a critical state, it can only result in a maximum neutron multiplication of $20\left(k_{\text {eff }}=0.95\right)$.

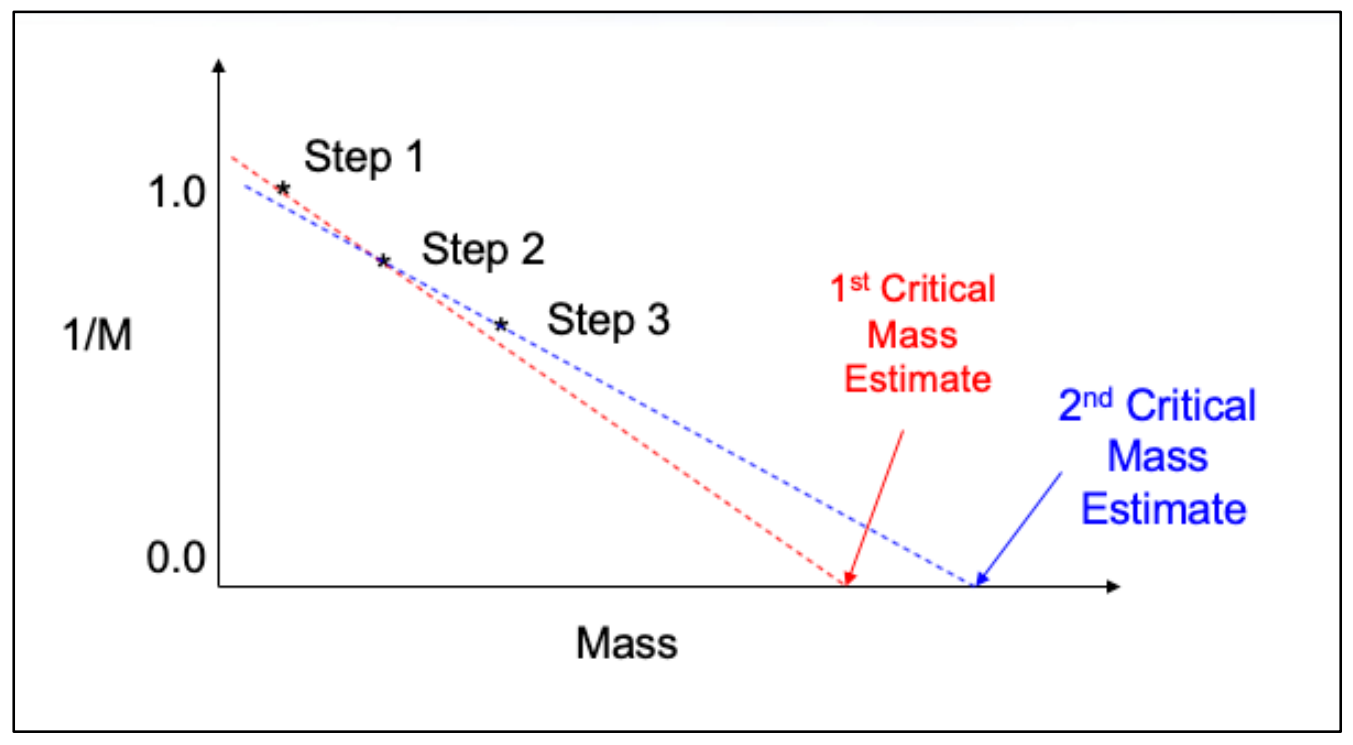

Figure 4. Plot of 1/M vs. mass for an approach-to-critical experiment.

For the ORSA, the approach-to-critical experiment will be stopped at a multiplication value of approximately 10, which is consistent with ANSI/ANS-1 [12] for hand-stacking operations of unknown assemblies and will ensure safety during these operations. This standard is not required for subcritical assemblies designed for a maximum neutron multiplication of 20, but it provides applicable guidance for similar experiments. 
Below are the rules to be considered for inclusion in the ORSA operating procedure once operations are approved:

1. Everyone is responsible for safety.

2. Generate the $1 / M$ critical approach curve as a "measure" of the critical point with the assembly.

3. Ensure that core multiplication is below 10, as required by ANSI/ANS-1 [12], for the hand stacking of unknown assemblies, which precludes worker safety concerns during operations.

4. Adhere to the "safe first and second loading rule," which requires that the first (no fissile loading) and second reactivity additions are always safe when personnel are present. Therefore, the first measurement corresponds to a core multiplication of 1.0, which corresponds to no fissile loading. The second measurement corresponds to the first fissile loading, and the third corresponds to the second fissile loading. These two measurement points make a line for the $1 / M$ plot to estimate the critical point.

5. Follow the halfway rule so that no single step addition of fissile mass, reflection, etc., shall go more than halfway to the estimated critical value.

6. Follow the three-quarter rule to ensure that no hand assembly step will be performed if the resulting active mass is greater than three-quarters of the estimated critical mass, or no hand assembly step will be performed if the resulting multiplication will exceed 10, corresponding to a $k_{\text {eff }}=0.9$. This guidance is from ANSI/ANS-1 [12].

These rules provide learning points for discussion throughout the hands-on training and ensure that operations will be safe (subcritical). In addition to implementation of these procedures, the ORSA will be designed to not achieve a neutron multiplication greater than $20\left(k_{\text {eff }}=0.95\right)$ during normal or credible abnormal conditions. 


\section{PROPOSED SUBCRITICAL ASSEMBLY SPECIFICATIONS}

The purpose of this section is to provide the ORSA design specifications and capabilities. This section will address the fissile materials needed for the ORSA and will specify where they will be obtained. This section will also discuss the required neutron reflectors and the configuration under which the subcritical experiments are to be performed. ORNL performed parametric studies to determine the quantity of fuel (uranium) needed with a particular neutron reflector configuration to enable subcritical measurements for a hands-on training course. The fuel quantity necessary for useful operations is also needed to determine compatibility with facility safety basis, security, and ORNL NCS requirements.

\subsection{AGN-201M REACTOR INTRODUCTION}

The AGN-201M (AGN) research reactor has been in operation for many years at various facilities, as well as college campuses hosting nuclear engineering programs. Figure 5 illustrates the entire AGN reactor unit and Figure 6 shows the configuration of the fuel plates, the control elements, and the graphite reflector in the core.

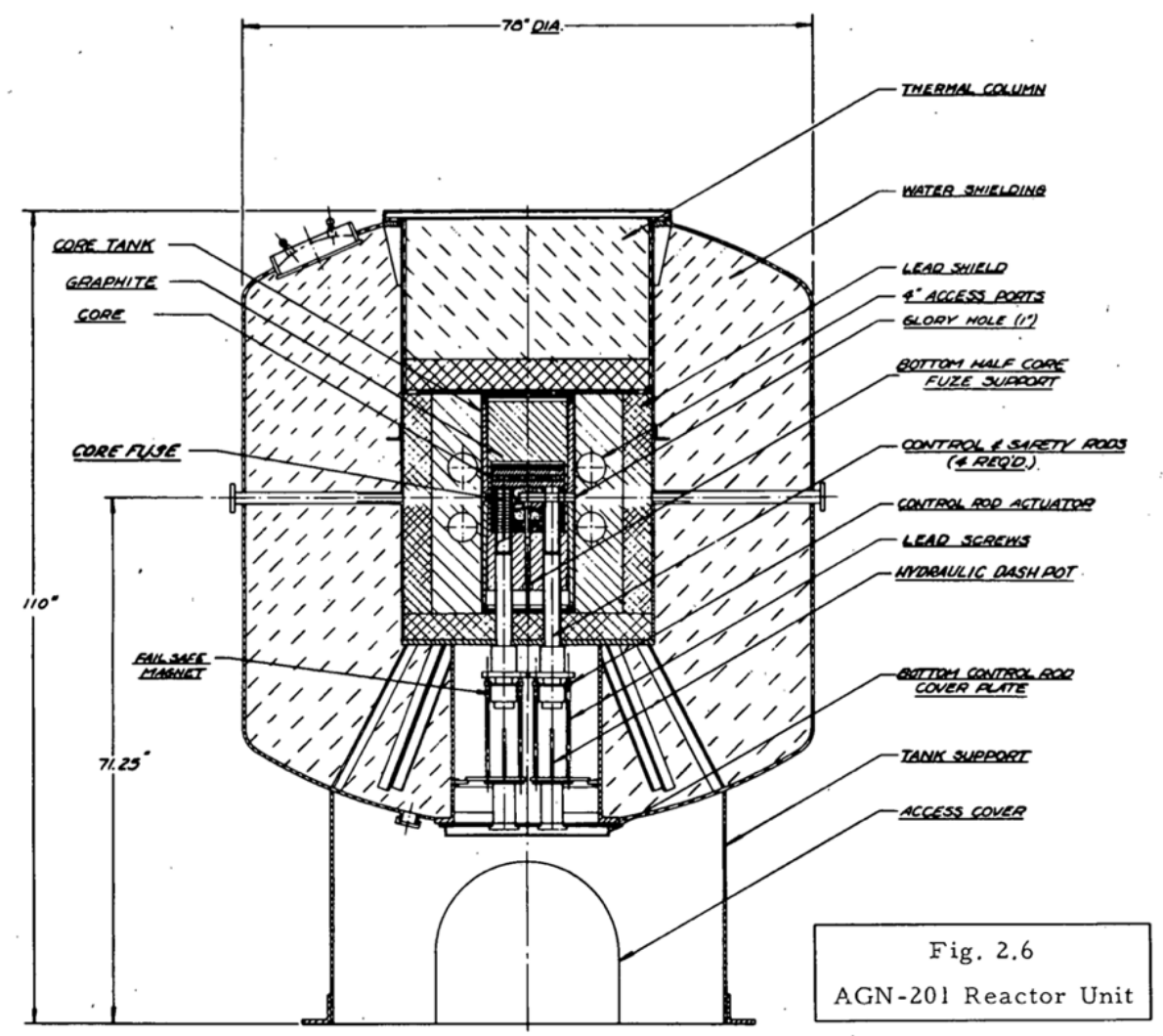

Figure 5. Illustration of the AGN reactor unit [8]. 


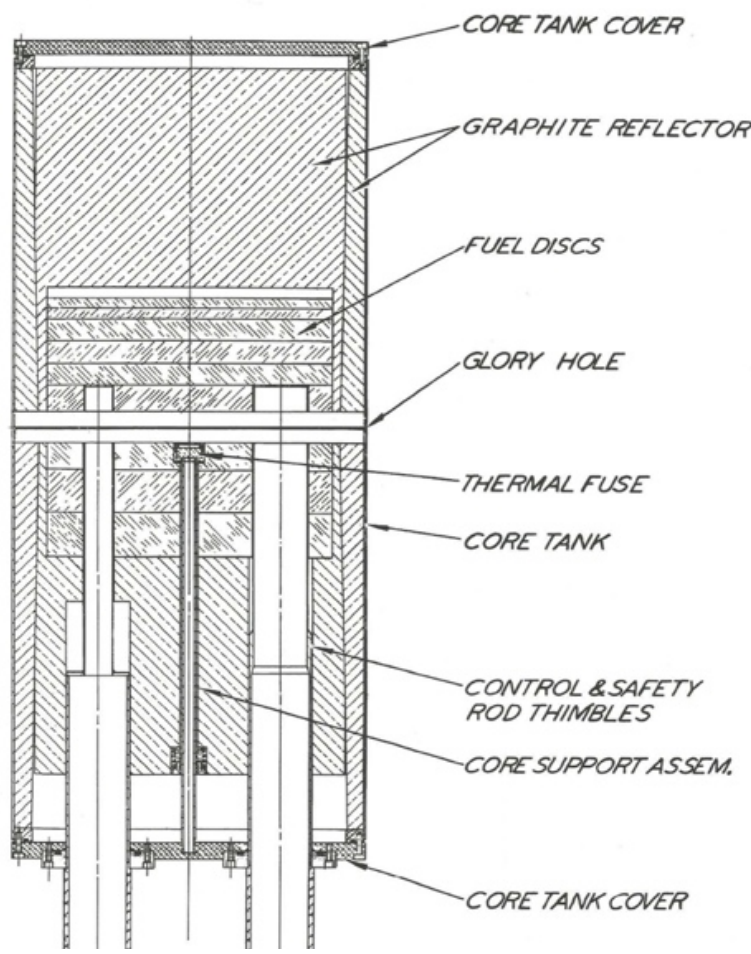

Figure 6. Figure 6. Illustration of the AGN reactor core [8].
The following description is from the dissertation by Bowen [9].

The AGN reactor was specifically designed for operation on university campuses, and it is considered to be one of the safest research reactors currently in use today. Biehl [8] noted the AGN reactor was designed as a low power $(0.1 \mathrm{~W})$ nuclear reactor in a compact, self-contained configuration. The core was designed to operate at delayed critical with a minimal quantity of fissile material, about 665 grams of ${ }^{235} U$, present in the form of uranium dioxide $\left(\mathrm{UO}_{2}\right)$ particles embedded in radiation-stabilized polyethylene. The uranium dioxide fuel is lowenriched uranium with a nominal enrichment of 19.5 \pm 0.5 weight percent ${ }^{235} U$. The AGN reactor is controlled using two safety rods (SR1 and SR2), one coarse control rod (CCR) and one fine control rod (FCR) which are driven into the core from the bottom of the reactor. The control rods are made of core fuel and are moved inside aluminum tubes present in the bottom half of the AGN core. The core is reflected by reactor-grade graphite, which has good neutron scattering characteristics, albeit less effective than hydrogen, but a lower tendency to absorb neutrons than hydrogen in water. Radiation

shielding for the AGN includes a lead shield outside of the graphite reflector for gamma ray shielding and a thick water shield outside of the lead layer to shield the thermal neutrons. These two radiation shields are adequate for AGN reactor operations at the design power of $0.1 \mathrm{~W}$. Additional cement block shielding installed around the UNM AGN reactor unit allow for operations at the licensed power of $5 \mathrm{~W}$. The reactor has four access ports that pass through the outer shielding and into the graphite reflector. These ports are used to place neutron sources or reactor instrumentation. A glory hole is also present for the introduction of experimental packages during operations or for the placement of neutron sources or other items during operations. Because dose rates are small during approved operations, the AGN can be operated via its control station inside the AGN reactor room without significant risk to students or the reactor operators.

Several AGN-201 research reactors are licensed in the United States at Idaho State University (ISU), Texas A\&M University, and the University of New Mexico (UNM). The AGN research reactor at UNM is used for a variety of purposes including undergraduate and graduate research and for training reactor operators. Fuel for several sites housing AGN research reactors (Catholic University of America, Idaho State University, University of Georgia, University of Memphis, University of Oklahoma, Naval Postgraduate School) has been moved to the Y-12 national security complex and could be available for use for this subcritical assembly. Operations with this research reactor include a variety of experimental measurements to determine neutron multiplication, excess reactivity, reactor period, control rod calibration, importance functions, reactor neutron temperature, neutron flux spatial distribution, and power calibration and detector dead-time. 


\subsection{FUEL DESCRIPTION}

As shown in the left image of Figure 7, the AGN core consists of 9 fuel plates with a gap at the top of the core for an additional $1 \mathrm{~cm}$ thick plate if needed to increase reactivity. The drawing illustrates how the fuel plates are stacked during operation in the AGN-201M. As shown in the photo and diagram on the right, the four $4 \mathrm{~cm}$ thick plates include holes for the fine control rod (FCR), safety rods (SRs), and coarse rod (CR) in the core. The SRs are inserted into the core in preparation for operations, the CR allows for coarse reactivity addition operations, and the FCR allows for very fine reactivity addition or removal during operations. Three $2 \mathrm{~cm}$ thick plates and two $1 \mathrm{~cm}$ thick plates are stacked on top of the $4 \mathrm{~cm}$ thick plates. The different thicknesses support approach-to-critical measurements. If a core fuse (not shown) melts during a reactivity excursion, then the aluminum baffle separates the lower and upper halves of the core, allowing for reactor shutdown. Of course, the ORSA will be designed to be subcritical for all normal operations and credible abnormal conditions.

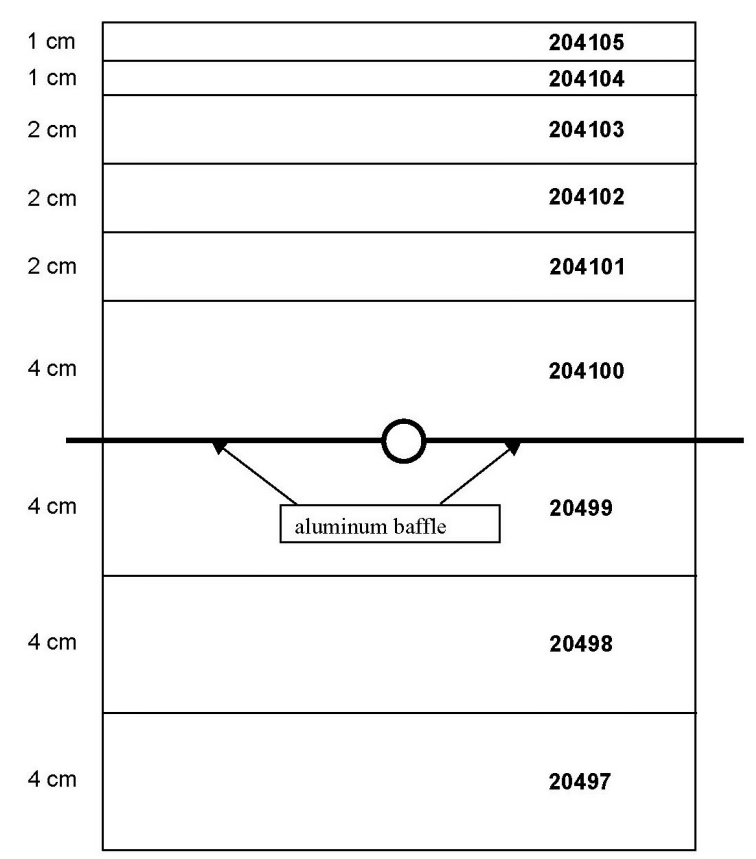

AGN-201M fuel disk stacking (The glory hole is the horizontal hole in the aluminum baffle providing access to the core)

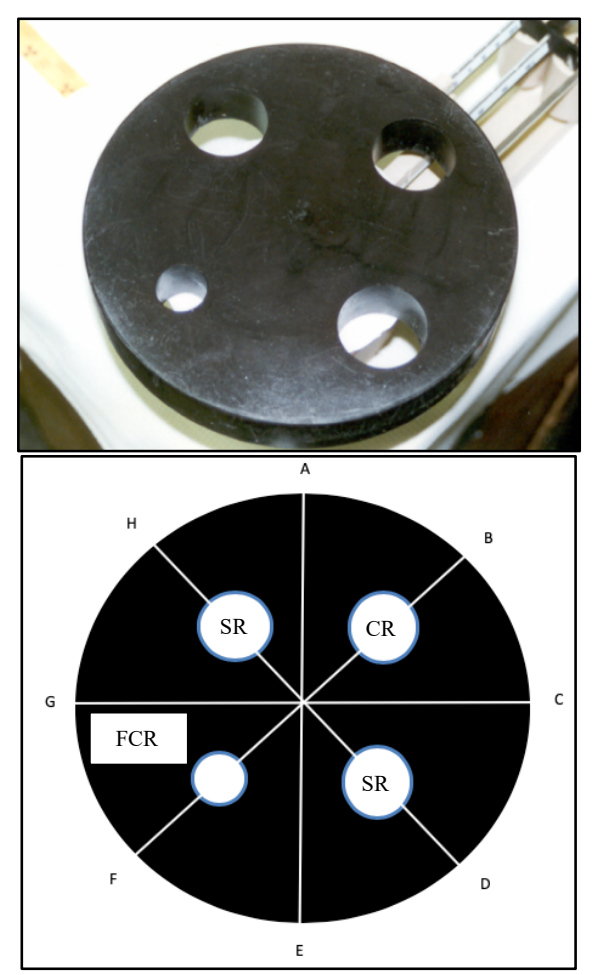

Photo of a lower core plate (top) and a diagram of the holes for the SR, FCR, and CR holes in plates 20497, 20498, 20499, and 204100 (bottom)

Figure 7. AGN-201M core showing fuel plate details [10].

To support the ORSA concept, a single core of AGN fuel would be required for the proposed operations. To support parametric studies for the feasibility of a subcritical assembly using AGN fuel, fuel specifications are needed. Fuel plate dimensions and mass specifications are provided in Table 1. The uranium in the fuel plates is made of high assay low enriched uranium (HALEU) with an enrichment of approximately $19.5 \pm 0.5$ weight percent ${ }^{235} \mathrm{U}$. The total ${ }^{235} \mathrm{U}$ content of the assembled AGN core is 620.7 grams. The fuel elements ( 2 SRs, 1 CCR and 1 FCR) contain a total of about $46.21 \mathrm{~g}^{235} \mathrm{U}$. 
Table 1. Fuel specifications for the AGN-201M [10]

\begin{tabular}{|c|c|c|c|c|}
\hline Piece & $\begin{array}{l}\text { Height } \\
\text { (cm) }\end{array}$ & Diameter (cm) & $\begin{array}{c}\text { Total mass } \\
\text { (grams) }\end{array}$ & $\begin{array}{c}{ }^{235} \text { U mass } \\
\text { (grams) }\end{array}$ \\
\hline \multicolumn{5}{|c|}{ Fixed fuel pieces } \\
\hline 20497 & 4 & 25.6 & $2,150.00$ & 98.89 \\
\hline 20498 & 4 & 25.6 & $2,158.50$ & 99.12 \\
\hline 20499 & 4 & 25.6 & $2,026.50$ & 93.17 \\
\hline 204100 & 4 & 25.6 & $2,052.00$ & 94.39 \\
\hline 204101 & 2 & 25.6 & $1,262.50$ & 58.01 \\
\hline 204102 & 2 & 25.6 & $1,263.50$ & 58.07 \\
\hline 204103 & 2 & 25.6 & $1,263.00$ & 58.05 \\
\hline 204104 & 1 & 25.6 & 670.00 & 30.80 \\
\hline 204105 & 1 & 25.6 & 648.50 & 29.79 \\
\hline Fuse & 0.9 & 2.2 & 5.86 & 0.41 \\
\hline Total ms & & & $13,500.36$ & 620.7 \\
\hline \multicolumn{5}{|c|}{ Movable fuel pieces } \\
\hline $\mathrm{SR}^{a}$ & 1 & 16 & 315.77 & 14.5 \\
\hline SR & 2 & 16 & 315.53 & 14.5 \\
\hline $\mathrm{CCR}^{b}$ & 16 & 4.5 & 315.58 & 14.5 \\
\hline $\mathrm{FCR}^{c}$ & 16 & 2.0 & 58.95 & 2.71 \\
\hline \multicolumn{2}{|c|}{ Total mass, $\mathrm{g}$} & & $1,005.83$ & 46.21 \\
\hline \multicolumn{2}{|c|}{ Total fuel mass, $\mathrm{g}$} & & $14,506.19$ & 666.91 \\
\hline
\end{tabular}

As mentioned above, holes in the lower $4 \mathrm{~cm}$ thick fuel plates accommodate the four control elements. To support $k_{\text {eff }}$ calculations, the specifications for each of the fuel plate penetrations are needed. Tables 2 and Table 3 provide the attributes of the upper and lower fuel plates, respectively. Appendix A from Bowen's dissertation provides the fuel plate penetration specifications to support $k_{\text {eff }}$ computations [9].

Table 2. Attributes of the AGN-201M upper fuel plates [10]

\begin{tabular}{|c|c|c|c|c|c|}
\hline Plate number & 204105 & 204104 & 204103 & 204102 & 204101 \\
\hline Plate diameter $(\mathrm{cm})$ & $25.603 \pm 0.058$ & $25.590 \pm 0.003$ & $25.633 \pm 0.002$ & $25.628 \pm 0.006$ & $25.633 \pm 0.003$ \\
\hline Plate height $(\mathrm{cm})$ & $1.039 \pm 0.013$ & $1.076 \pm 0.009$ & $2.004 \pm 0.013$ & $2.005 \pm 0.015$ & $2.022 \pm 0.020$ \\
\hline Mass $(\mathrm{g})$ & $653.730 \pm 0.030$ & $675.767 \pm 0.030$ & $1268.197 \pm 0.030$ & $1269.150 \pm 0.030$ & $1270.437 \pm 0.030$ \\
\hline $\begin{array}{l}\text { Calculated volume } \\
\left(\mathrm{cm}^{3}\right)\end{array}$ & $535.1 \pm 9.105$ & $553.4 \pm 4.892$ & $1034.4 \pm 6.895$ & $1034.4 \pm 8.315$ & $1043.6 \pm 10.677$ \\
\hline $\begin{array}{l}\text { Calculated density } \\
\left(\mathrm{g} / \mathrm{cm}^{3}\right)\end{array}$ & $1.222 \pm 0.021$ & $1.221 \pm 0.011$ & $1.226 \pm 0.008$ & $1.227 \pm 0.010$ & $1.217 \pm 0.013$ \\
\hline
\end{tabular}

Table 3. Attributes of the AGN-201M lower fuel plates [10]

\begin{tabular}{lcccc}
\hline Plate number & $\mathbf{2 0 4 1 0 0}$ & $\mathbf{2 0 4 9 9}$ & $\mathbf{2 0 4 9 8}$ & $\mathbf{2 0 4 9 7}$ \\
\hline Plate diameter $(\mathrm{cm})$ & $25.559 \pm 0.030$ & $25.611 \pm 0.060$ & $25.659 \pm 0.143$ & $25.692 \pm 0.200$ \\
Plate height $(\mathrm{cm})$ & $3.968 \pm 0.014$ & $3.994 \pm 0.034$ & $4.005 \pm 0.034$ & $3.982 \pm 0.026$ \\
SR 1 hole diameter $(\mathrm{cm})$ & $5.076 \pm 0.007$ & $5.074 \pm 0.049$ & $5.163 \pm 0.068$ & $5.121 \pm 0.009$ \\
SR 2 hole diameter $(\mathrm{cm})$ & $5.078 \pm 0.030$ & $5.114 \pm 0.004$ & $5.109 \pm 0.009$ & $5.102 \pm 0.032$ \\
CCR hole diameter $(\mathrm{cm})$ & $5.046 \pm 0.024$ & $5.096 \pm 0.021$ & $5.113 \pm 0.006$ & $5.105 \pm 0.003$ \\
FCR hole diameter $(\mathrm{cm})$ & $2.844 \pm 0.054$ & $2.951 \pm 0.000$ & $2.948 \pm 0.002$ & $2.937 \pm 0.012$ \\
Glory hole span $(\mathrm{cm})$ & $2.910 \pm 0.000$ & $3.007 \pm 0.039$ & - & - \\
Glory hole depth $(\mathrm{cm})$ & 1.45 & 1.503 & - & - \\
Mass $(\mathrm{g})$ & $2058.333 \pm 0.030$ & $2033.240 \pm 0.030$ & $2163.353 \pm 0.030$ & $2155.887 \pm 0.030$ \\
Calculated volume $\left(\mathrm{cm}^{3}\right)$ & $1685.4 \pm 4.275$ & $1682.9 \pm 5.690$ & $1787.7 \pm 6.818$ & $1785.0 \pm 7.062$ \\
Calculated density $\left(\mathrm{g} / \mathrm{cm}^{3}\right)$ & $1.221 \pm 0.003$ & $1.208 \pm 0.004$ & $1.210 \pm 0.005$ & $1.208 \pm 0.005$ \\
\hline
\end{tabular}




\subsubsection{Subcritical Assembly Fuel Availability}

For proposal \#1 (Appendix A), NCSP funding was provided to Y-12 and ORNL for researching lowenriched fuel availability at Y-12 and for the feasibility study at ORNL [7]. Y-12 spent approximately one year searching their Material Control and Accountability (MC\&A) system for the supply of low-enriched fuel, and their staff members found multiple AGN-201M fuel materials that can be used for the ORSA, as summarized in Table 4. The Y-12 inventory list is provided in Appendix B. The AGN-201M core materials consist of low-enriched uranium (LEU) with approximately $19.5 \pm 0.5$ weight percent ${ }^{235} \mathrm{U}$ (HALEU). Consequently, this HALEU material has a special nuclear material (SNM) category of IV with an "E" attractiveness, indicating that it is low risk material from a security standpoint.

Table 4. AGN-201M research reactor fuel and components for the ORSA

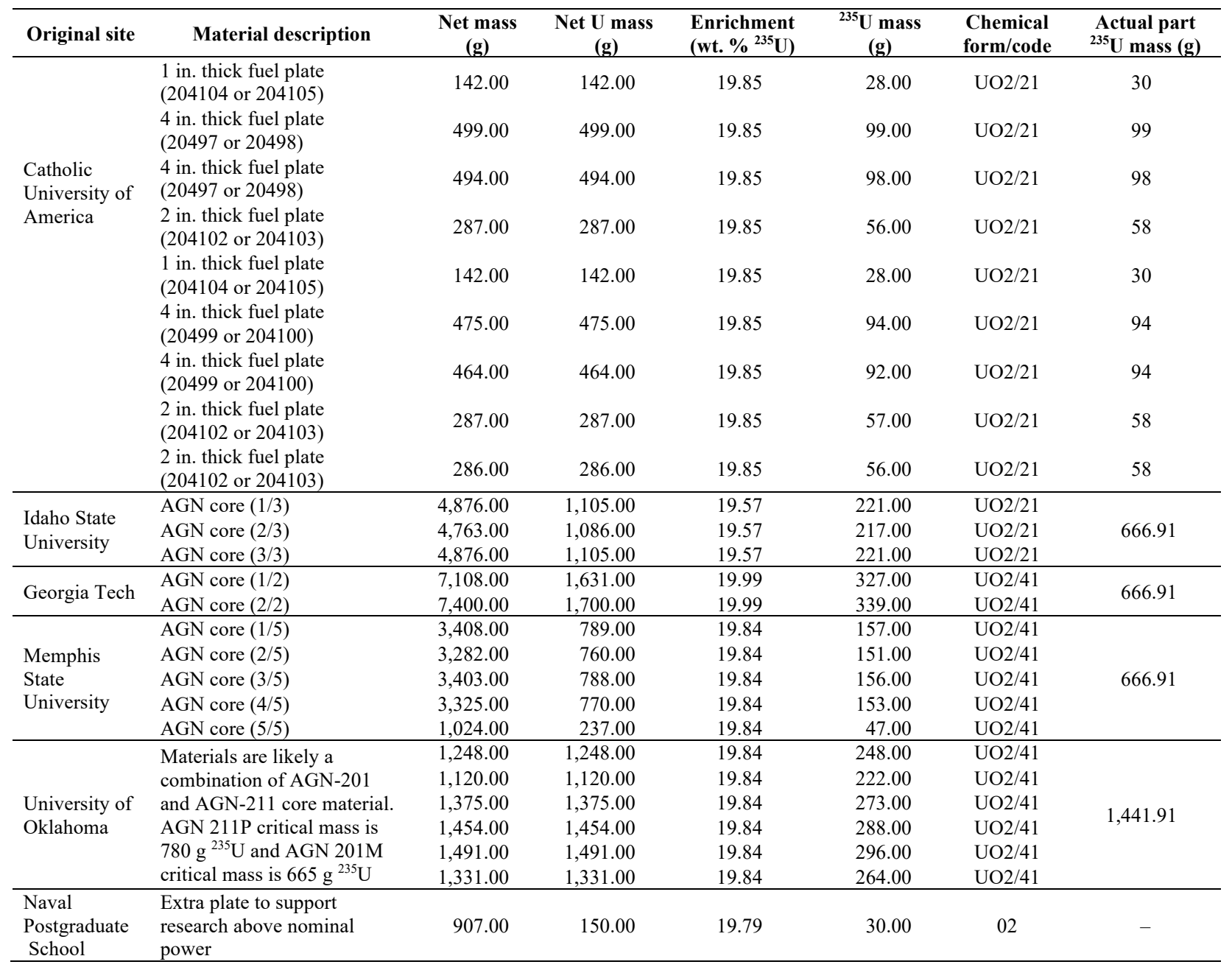

Based on the review of the Y-12 information, it appears that at least four complete AGN cores are available. Because these parts alone have never been assembled beyond the research reactor design, parametric studies are required to ensure that subcritical experiments can be conducted with the available fuel materials to support sponsor/national needs. The AGN core materials alone cannot be used for these experiments, but the core material with a minimal neutron absorbing neutron reflector will allow for effective neutron multiplication measurements to illustrate the importance of NCS parameters in the subcritical experiment. This subcritical assembly concept should be able to illustrate the effect of fissile material mass, neutron moderation, neutron interaction, neutron reflection, neutron absorption, and 
system shape/geometry. The remaining report sections consider the use of the Y-12 AGN core pieces with conceptual neutron reflector designs to ensure that the concept is feasible to progress to a design stage.

\subsection{Neutron Reflectors for the Subcritical Assembly}

A single AGN core is needed to support the ORSA for training operations. The core plates will be stacked in a vertical arrangement. To achieve a sufficiently high neutron multiplication for the assembly to be useful as a training assembly, a suitable neutron reflector must be considered. To achieve a critical mass below the minimum critical mass of uranium at an optimum moderation of $\sim 800$ grams of ${ }^{235} \mathrm{U}$, the AGN research reactor uses reactor-grade graphite due to its ability to reflect, rather than to absorb, some of the neutrons that leak out of and back into the core. This will result in an increase in neutron production. For this study, various neutron reflectors were considered to determine the most suitable type and geometrical configuration needed to support the proposed operations. Ideally, the subcritical assembly reflector materials could be fabricated at the ORNL Material Demonstration Facility (MDF).

\subsection{Parametric Studies}

Parametric studies were performed based on the specifications of the AGN-201M research reactor core fuel, neutron reflector configurations, and proposed ORSA operations. These studies were performed using the KENO VI code in the SCALE 6.2.3 package [11]. Scripts were used to automate the steps to set up KENO VI input files for the various configurations and materials and to compile calculation results from KENO VI output files. The ENDF/B-VII.1 library was used for these calculations.

\subsubsection{Core \& Reflector Parametric Study}

This study was performed to examine whether it is feasible to conduct subcritical measurements using a single AGN-201M core, with and without the control rods present, with a variety of proposed reflectors. At the time this study was performed, it was thought that at least a single AGN-201M core was available, but it now appears that at least four AGN cores are available to support this activity. The core stack is identical to that shown in Figure 7, except the aluminum baffle plate was not considered in the calculations. The following neutron reflectors were considered for this parametric study for thicknesses of $5,15,30$, and $60 \mathrm{~cm}$ :

- Aluminum

- Beryllium metal

- Beryllium oxide

- Copper

- Graphite

- Light water
- Paraffin

- Plexiglas

- Polyethylene

- Stainless steel

- Uranium (depleted - 0.27 wt. $\%{ }^{235} \mathrm{U}$ enrichment)

It is not known whether the AGN control rod fuel materials are available for these proposed operations, so the parametric study was repeated with voided regions in the locations where the control rods would be inserted and removed from the core in the research reactor configuration. For ORSA operations, it is desired to know if operations could be conducted without the additional reactivity of the control rods in the core. Therefore, if the computations indicate that an appropriate level of neutron multiplication could be achieved for a subset of the reflector materials without the control rods, then ORSA could have a simplified design with a minimum number of components. The goal of this parametric study is to determine if an AGN-201M core with a practical level of reflector thickness can achieve a useful level of neutron multiplication for the ORSA to be useful as a hands-on training device. The next parametric study will go a step further and examine particular reflector types and thickness to hone in on the desired amount of neutron multiplication. Figure 8 illustrates the geometry considered for this parametric study. 
Figures 9 and 10 provide the KENO VI mean $k_{\text {eff }}$ results as a function of reflector type and the thickness for each case illustrated in Figure 8 (lower AGN-201M fuel plate holes filled with fissile material or empty holes). Materials needed to fill the fuel plate control, safety and fine control rod holes will need to be fabricated to support the experiments. All $k_{\text {eff }}$ results had standard deviations of less than 0.00015 . KENO cases assumed 1100 generations with 10,000 neutrons per generation and skipping 100 generations.

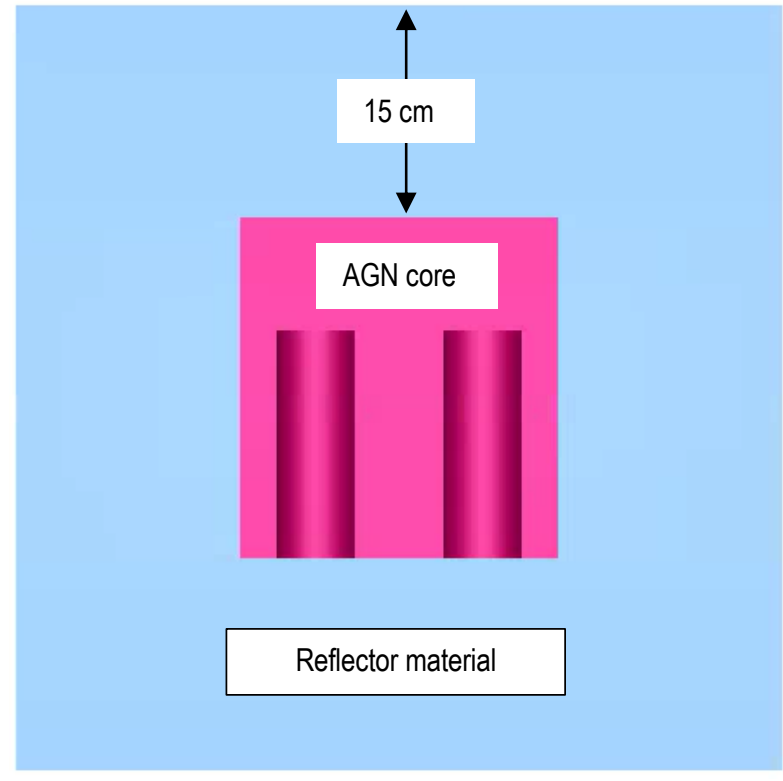

AGN core stack with control rod holes empty with a $15 \mathrm{~cm}$ thick neutron reflector

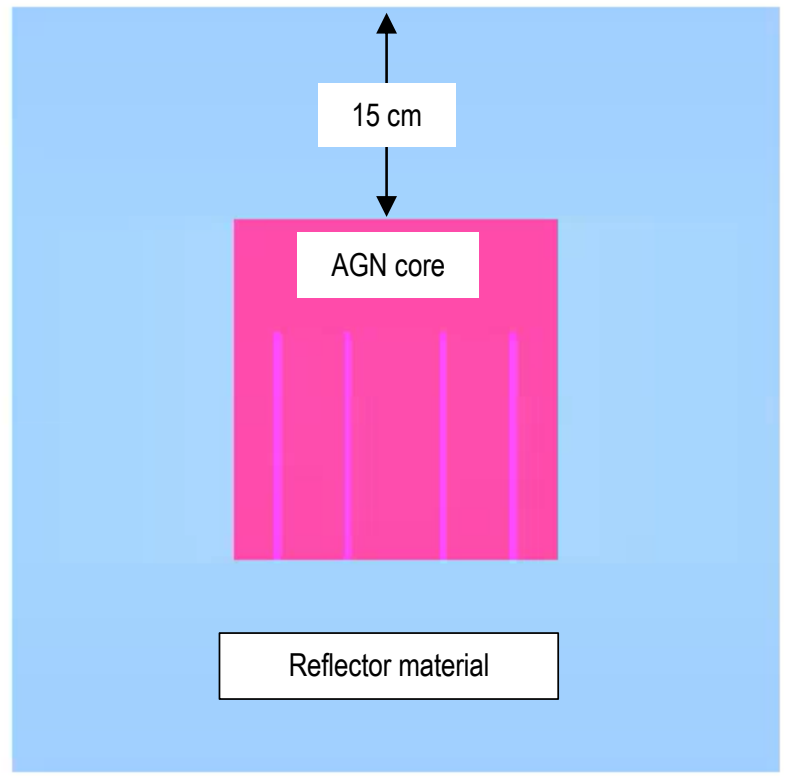

AGN core stack with control rod hole filled with fuel with a $15 \mathrm{~cm}$ thick neutron reflector

Figure 8. AGN-201M core with core control holes empty and filled.

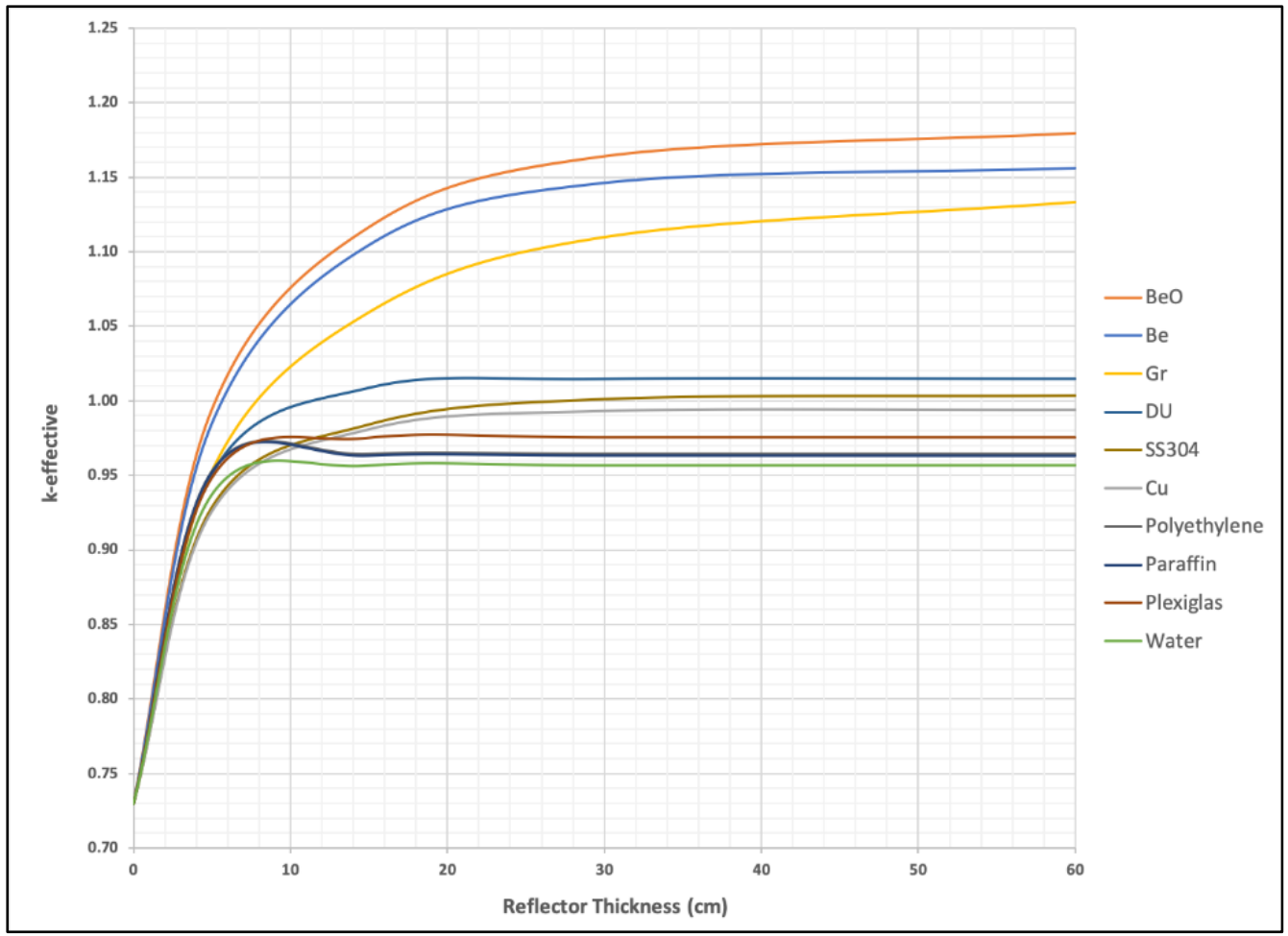


Figure 9. AGN-201M core with core control holes filled.

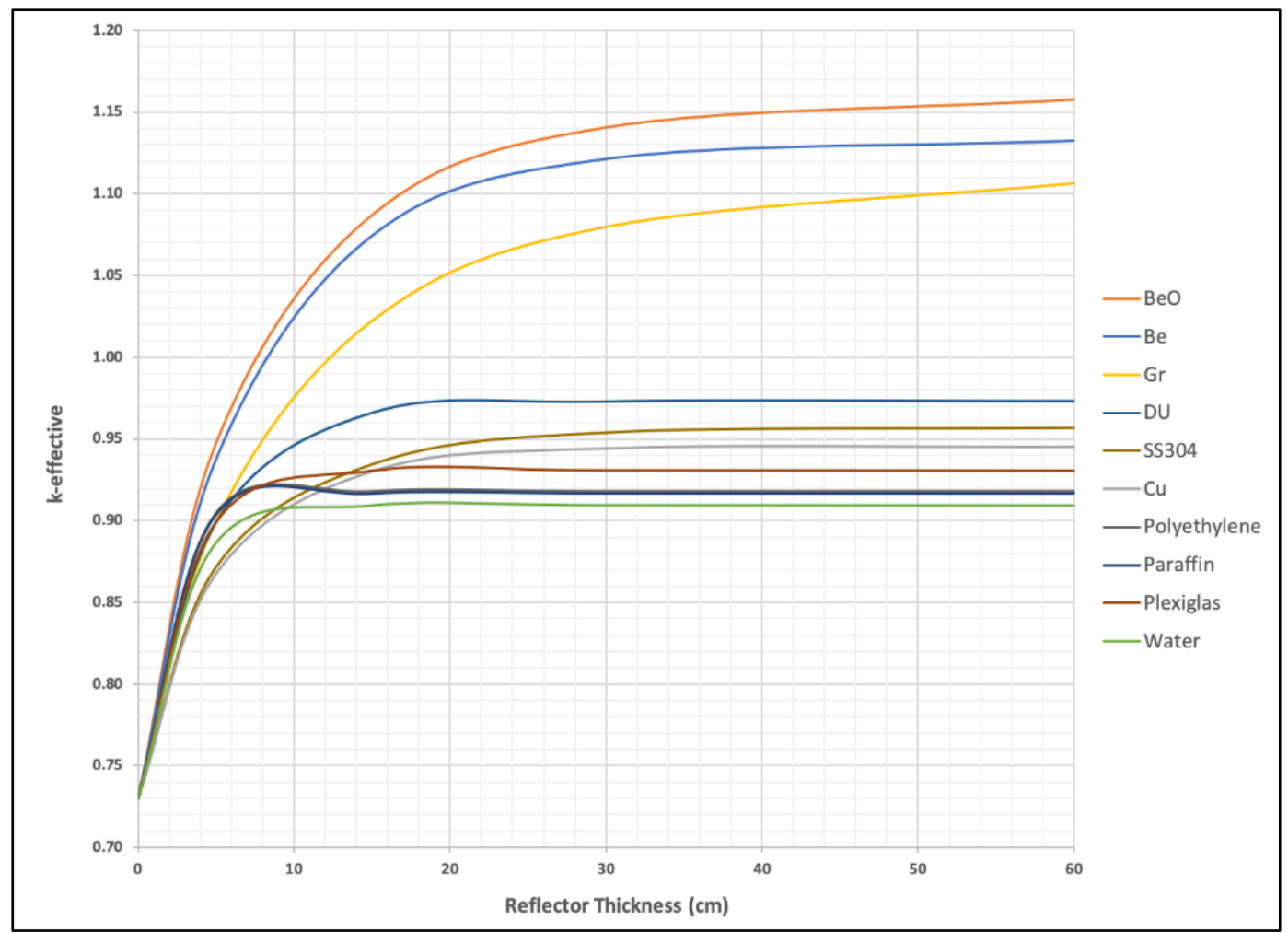

Figure 10. AGN-201M core with core control holes empty.

As shown in Figure 10, the results for the core with empty control rod holes indicate that $\mathrm{Be}, \mathrm{BeO}$ and graphite having the best reflector worth for this particular core and configuration, and they provide the highest $k_{\text {eff }}$ and neutron multiplication. The same trend is true for the core results with filled control rod holes. Beryllium requires special mitigative controls in facilities for worker safety, and unless the beryllium is enclosed, it can pose a human health hazard. Therefore, graphite was chosen to carry forward in this feasibility study, because a thin graphite reflector may provide sufficient neutron reflection to result in sufficient neutron multiplication, $M$, to perform effective hands-on training experiments. Figure 11 shows the results of additional KENO VI calculations to examine the thickness of graphite around the core $(5 \mathrm{~cm}$ at the bottom of the core, with varying graphite thickness radially and on the top of the ORSA core 5-15 cm). A thinner reflector on the bottom is assumed so that it will not be too tall for mounting on a table or stand. 


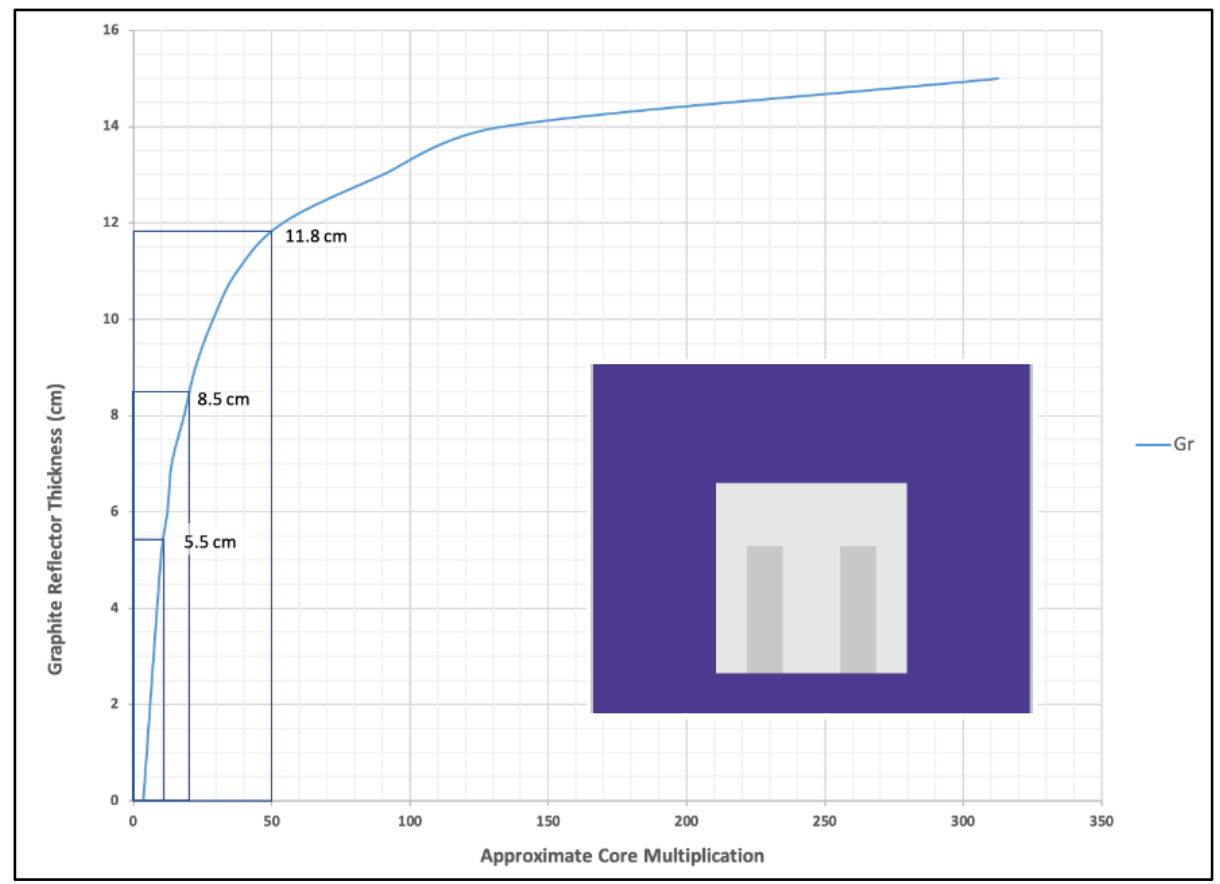

Figure 11. Graphite reflector core multiplication KENO VI results.

The results for ORSA core multiplication as a function of graphite reflector thickness indicates that a multiplication of 10 can be achieved with a thickness of approximately $5.5 \mathrm{~cm}$ (2.17 in.), a multiplication of 20 with a thickness of about $8.5 \mathrm{~cm}$ (3.4 in.) and a multiplication of 50 with a thickness of $11.8 \mathrm{~cm}$ (4.7 in.). These results are summarized in Table 5, along with the reflector mass for each result.

Table 5. Graphite reflector summary

\begin{tabular}{ccc}
\hline $\begin{array}{c}\text { Graphite top and radial } \\
\text { thickness, cm (in.) }\end{array}$ & $\begin{array}{c}\text { Reflector } \\
\text { mass, } \mathbf{g}(\mathbf{l b})\end{array}$ & $\begin{array}{c}\text { Resulting core } \\
\text { approximate } \\
\text { multiplication, } \mathbf{M}\end{array}$ \\
\hline $5.5(2.2)$ & $55,071(121.41)$ & 10 \\
$8.5(3.4)$ & $94,520(208.38)$ & 20 \\
$11.8(4.7)$ & $149,993(330.68)$ & 50 \\
\hline
\end{tabular}

Based on the results in Table 5, the ORSA concept is feasible with AGN-201M core material and approximately $8.5 \mathrm{~cm}$ thick (3.4 in.) graphite reflector. The weight, $\sim 94 \mathrm{~kg}(208 \mathrm{lb})$, and size of this critical assembly concept is relatively small, so this system is not expected to be large or bulky. The outside diameter of the core and reflector is $37.5 \mathrm{~cm}$ (14.8 in.) and the height is $42.6 \mathrm{~cm}$ (16.8 in.). Approximately 620 grams of ${ }^{235} \mathrm{U}$ are present in the core. Conceptually, the assembly is small enough to reside on a moveable platform, stand, or table for experiments. Furthermore, the core plates and reflector shells are small enough for easy handling during hands-on training. The next parametric study considered one potential procedure to build the subcritical assembly to measure neutron multiplication.

\subsubsection{Subcritical Assembly: Effect of Fissile Mass and Neutron Reflection}

A parametric study was performed on the conceptual hands-on operations of the ORSA to demonstrate the addition of fissile mass. These computations were performed to verify that the core multiplication would be sufficient to complete the hands-on portion of the experiments. The approach-to-critical procedure is methodical and allows for small, incremental increases in reactivity during operations. The procedure for the conceptual hands-on experiment is presented in Table 6. 
Table 6. Hands-on experiment assembly procedure

\begin{tabular}{|c|c|c|}
\hline Step \# & Illustration & Description \\
\hline 1 & & $\begin{array}{l}\text { - Four stacked } 4 \mathrm{~cm} \text { thick AGN-201M core plates } \\
\text { - SRs, CCR, and FCRs have been emptied of fuel (void) } \\
\text { - No reflector material has been added to the assembly in } \\
\text { this step } \\
\text { - }{ }^{235} \mathrm{U} \text { mass: } 385.57 \mathrm{~g}\end{array}$ \\
\hline 2 & & $\begin{array}{l}\text { - Same configuration as Step } 1 \\
\text { - One } 2 \mathrm{~cm} \text { thick AGN-201M core plate added } \\
\text { - } 8.5 \mathrm{~cm} \text { thick graphite reflector added radially and on } \\
\text { top of the assembly } \\
\text { - } 5.0 \mathrm{~cm} \text { thick graphite reflector added on the bottom of } \\
\text { the assembly } \\
\text { - }{ }^{235} \mathrm{U} \text { mass: } 443.58 \mathrm{~g}\end{array}$ \\
\hline 3 & & $\begin{array}{l}\text { - Same configuration as Step } 1 \\
\text { - Two } 2 \mathrm{~cm} \text { thick AGN-201M core plates added } \\
\text { - } 8.5 \mathrm{~cm} \text { thick graphite reflector added radially and on } \\
\text { top of the assembly } \\
\text { - } 5.0 \mathrm{~cm} \text { thick graphite reflector added on the bottom of } \\
\text { the assembly } \\
\text { - }{ }^{235} \mathrm{U} \text { mass: } 501.65 \mathrm{~g}\end{array}$ \\
\hline 4 & & $\begin{array}{l}\text { - Same configuration as Step } 1 \\
\text { - Three } 2 \mathrm{~cm} \text { thick AGN-201M core plates added } \\
\text { - } 8.5 \mathrm{~cm} \text { thick graphite reflector radially and on top of } \\
\text { the assembly } \\
\text { - } 5.0 \mathrm{~cm} \text { thick graphite reflector added on the bottom of } \\
\text { the assembly } \\
\text { - }{ }^{235} \mathrm{U} \text { mass: } 559.70 \mathrm{~g}\end{array}$ \\
\hline 5 & & $\begin{array}{l}\text { - Same configuration as Step } 4 \\
\text { - One } 1 \mathrm{~cm} \text { thick AGN-201M core plate added } \\
\text { - } 8.5 \mathrm{~cm} \text { thick graphite reflector added radially and on } \\
\text { top of the assembly } \\
\text { - } 5.0 \mathrm{~cm} \text { thick graphite reflector added on the bottom of } \\
\text { the assembly } \\
\text { - }{ }^{235} \mathrm{U} \text { mass: } 590.50 \mathrm{~g}\end{array}$ \\
\hline 6 & & $\begin{array}{l}\text { - Same configuration as Step } 4 \\
\text { - Two } 1 \mathrm{~cm} \text { thick AGN-201M core plates added } \\
\text { - } 8.5 \mathrm{~cm} \text { thick graphite reflector added radially and on } \\
\text { top of the assembly } \\
\text { - } 5.0 \mathrm{~cm} \text { thick graphite reflector added on the bottom of } \\
\text { the assembly } \\
\text { - }{ }^{235} \mathrm{U} \text { mass: } 620.29 \mathrm{~g}\end{array}$ \\
\hline
\end{tabular}

The ORSA is to be mounted on a table or mobile platform to conduct the experiments. The core plates are subject to NCS limits and must be controlled in accordance with implemented NCS limits. The core assembly steps will be controlled via in-hand operating procedure. The intent of each step is to add 
sufficient mass to approach the core multiplication limit of 10 or $20, k_{\text {eff }}$ of 0.90 or 0.95 , respectively. As the ORSA operations are inherently subcritical, the assembly will not generate any heat during operations and will remain at room temperature during these experiments. The results of the parametric study are shown in Figure 12.

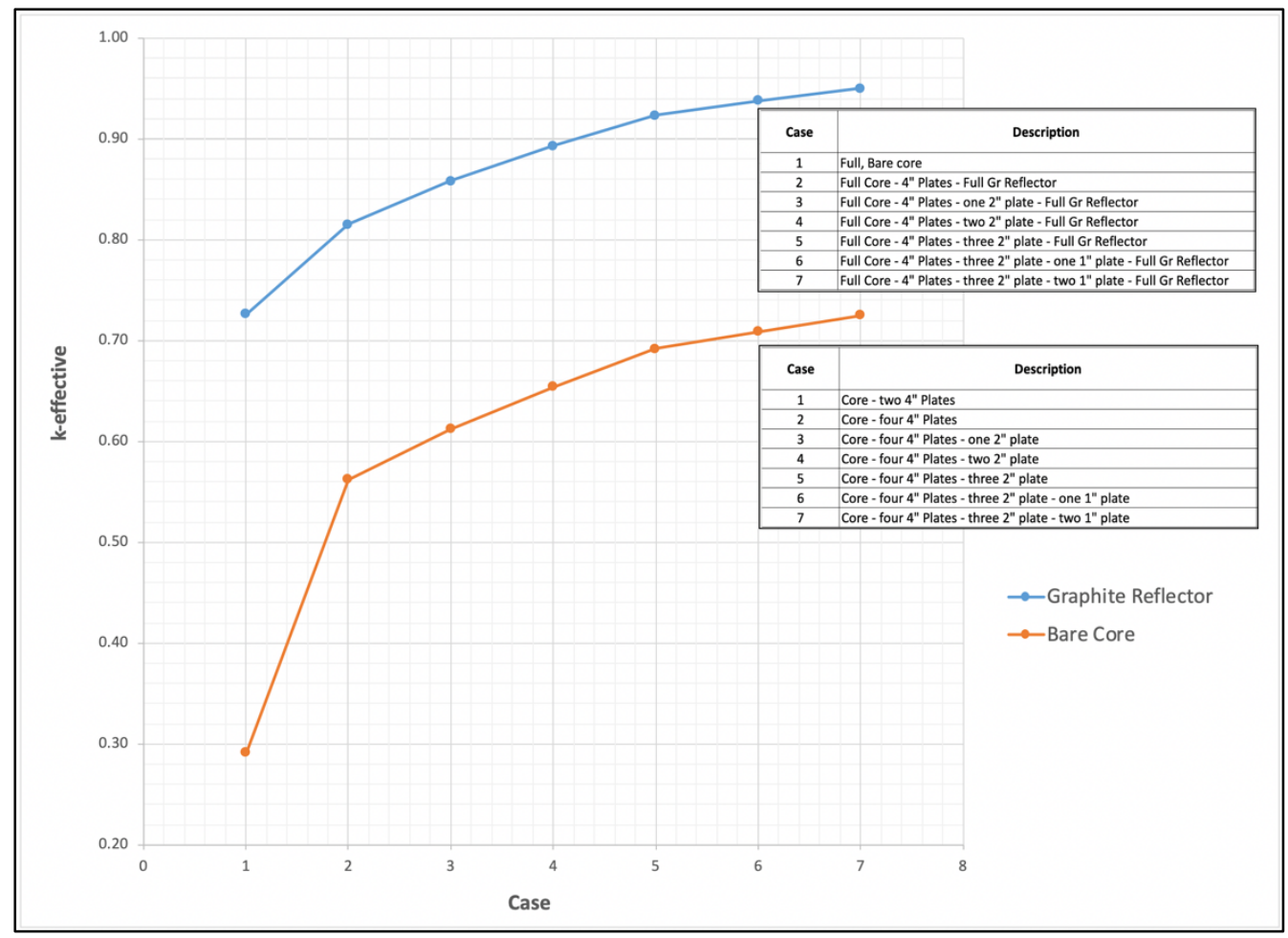

Figure 12. Mean KENO VI $\boldsymbol{k}_{\text {eff }}$ results: fissile mass approach-to-multiplication limit.

The results show that the entire AGN-201M in a bare configuration - with no neutron reflector-is amply subcritical, with a $k_{\text {eff }}$ of 0.72 . Graphite was chosen as the key neutron reflector for the ORSA because of its ability to scatter neutrons with low neutron absorption. The combination of the $\mathrm{UO}_{2}$-polyethylene matrix and the graphite reflector allow for sufficient neutron multiplication to demonstrate the effects of adding fissile mass to the core assembly. The graphite reflector results indicate an average increase in the $k_{\text {eff }}$ of $34.6 \%$. The results also indicate that an ORSA multiplication of $10\left(k_{\text {eff }}=0.90\right)$ is achieved with four $4 \mathrm{~cm}$ and two $2 \mathrm{~cm}$ fuel plates $\left({ }^{235} \mathrm{U}\right.$ mass of 501.65 grams $)$, and an ORSA multiplication of $20\left(k_{\text {eff }}=\right.$ $0.95)$ is achieved with four $4 \mathrm{~cm}$ plates, three $2 \mathrm{~cm}$ plates, and two $1 \mathrm{~cm}$ plates $\left({ }^{235} \mathrm{U}\right.$ mass of 620.29 grams). These calculations assume an $8.5 \mathrm{~cm}$ thick graphite reflector radially and on top of the assembly. The bottom of the assembly has a graphite thickness of $5 \mathrm{~cm}$, which is assumed as a starting point. The lower graphite plate will be used as a platform on which to build the ORSA subcritical assembly. This experiment is certainly feasible to support hands-on experiments, and Case 7 (Figure 12) with graphite reflection is now the base configuration for the ORSA.

\subsubsection{Subcritical Assembly Approach-to-Multiplication Limit Parametric Study: Interaction}

A parametric study was performed to examine neutron interaction with the base ORSA configuration. The core of the AGN-201M was designed to be split in the center of the assembly as a shutdown mechanism. For the hands-on training, students attending this course will benefit from splitting the core into the top (all $2 \mathrm{~cm}$ thick and $1 \mathrm{~cm}$ thick plates) and bottom (all $4 \mathrm{~cm}$ thick plates) and experimentally determining how the ORSA multiplication changes as a result of the proximity of the two core pieces. In reality, this 
would mimic process operations with fissionable materials when operators handle multiple uranium parts and neutron interaction. The parametric study starts with the top and bottom core pieces separated by 10 $\mathrm{cm}$ and continues until the two core pieces are closed. The modeled configuration is illustrated in Figure 13, and the results are presented in Figure 14.

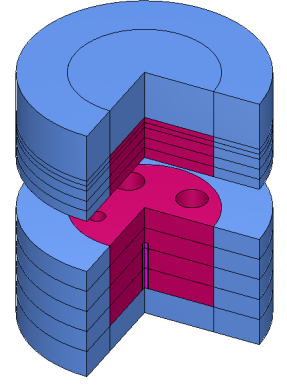

Upper and lower core spacing separation $-10 \mathrm{~cm}$

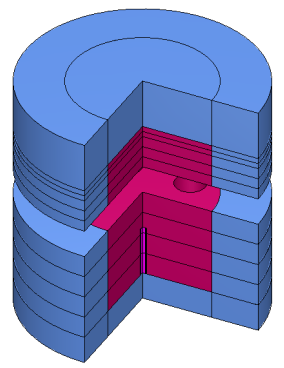

Upper and lower core spacing separation $-5 \mathrm{~cm}$

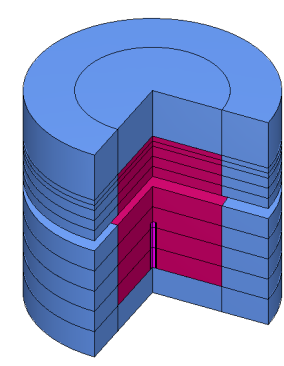

Upper and lower core spacing separation $-2 \mathrm{~cm}$

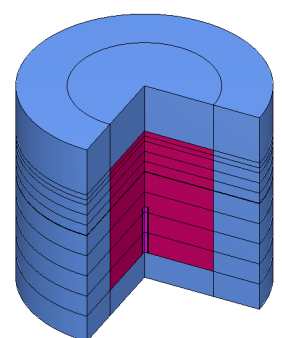

Upper and lower core spacing separation $-0.1 \mathrm{~cm}$

Figure 13. Illustration of KENO VI geometry.

Figure 13 shows the need for the ORSA to have a vertical split-table that allows for automatic or manual core splitting and assembly. For the sake of regular hands-on operations, it would be prudent to design the system to allow for hands-on assembly operations with the core separated to allow for personnel safety while allowing for a multiplication of 20 for the benefit of the training course.

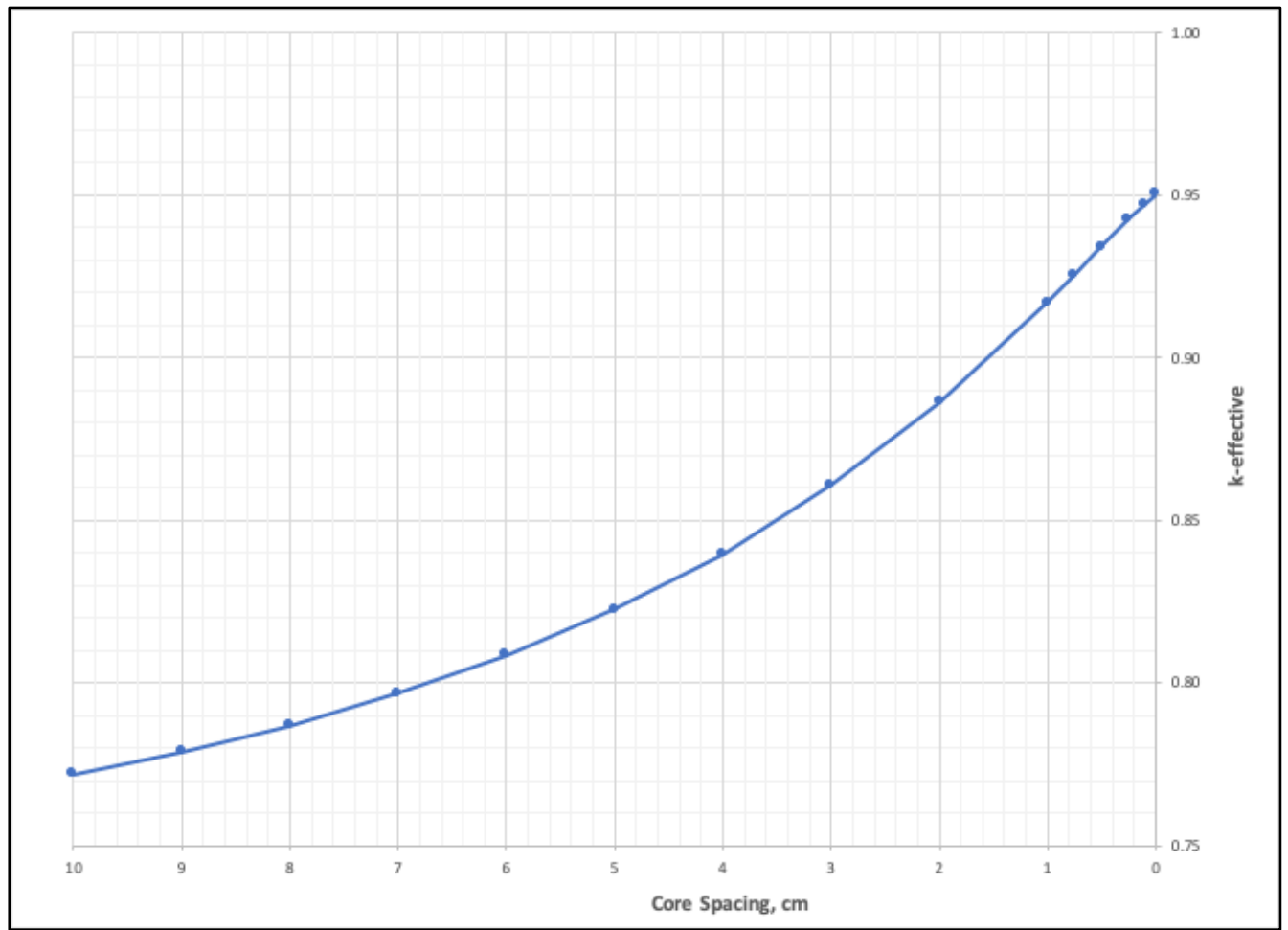

Figure 14. Mean KENO VI $k_{\text {eff }}$ results: interaction parametric study. 
The interaction study results indicate that the core halves with $10 \mathrm{~cm}(3.9 \mathrm{in}$.) in between them is amply subcritical. Neutron interaction increases as the distance between the two core halves is decreased. The interaction probability (neutrons that leak out of the top half of the core enter the bottom half of the core) increases, consequently increasing the likelihood of more neutron production from fission. As the closure distance is varied from $10 \mathrm{~cm}$ (3.9 in.) to zero, the neutron multiplication increases to the core multiplication of the fully loaded graphite-reflected core shown in Figure $11\left(k_{\text {eff }}=0.95\right.$, or $\left.\mathrm{M}=20\right)$. This computation indicates that the interaction parameter can be explored as part of the hands-on training experiments.

\subsubsection{Subcritical Assembly Void Replacement Study: Moderation}

This parametric study examined the change to ORSA design by replacing the void regions in the CCR, SR, and FCR holes with polyethylene. The AGN-201M research reactor was designed to be an optimally moderated thermal system. Because the configuration has been modified from its original purpose, this study analyzed the effect of adding more moderating material to the ORSA core and also determined whether the new configuration is under- or over-moderated. Because the core plates are made of polyethylene, high density polyethylene (HDPE) was chosen for this study. The students in the course will be required to estimate whether the core is under-moderated, over-moderated, or optimally moderated after a neutronics lecture. The HDPE is then added to the control element holes, and measurements are made to estimate the core multiplication. The control element holes are filled as shown in Figure 15. The results of this parametric study are provided in Table 7.

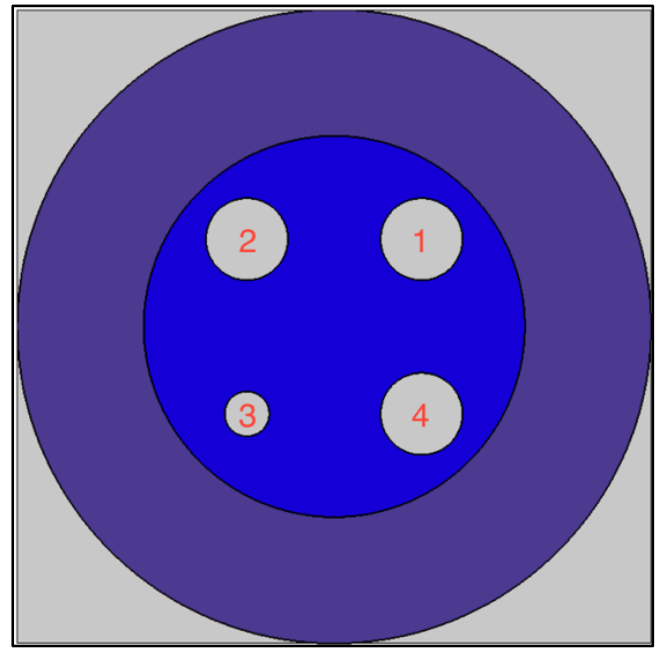

Figure 15. ORSA control rod hole map (1 - CR; 2 \& 4 - SR1 \& SR2; 3 - FCR).

Table 7. Moderation parametric study results

\begin{tabular}{|c|c|c|c|c|c|c|c|c|c|}
\hline $\begin{array}{c}\text { Neutron } \\
\text { absorbing } \\
\text { material }\end{array}$ & CR & SR & FCR & SR & $\boldsymbol{k}_{\text {eff }}$ & sigma & $\begin{array}{c}\text { Calculated } \\
\text { neutron } \\
\text { multiplication, } \\
M\end{array}$ & $\begin{array}{c}\text { Change in } \\
\text { calculated } \\
\text { multiplication, } \\
\Delta M\end{array}$ & $\begin{array}{c}\text { Cumulative } \\
\text { change in } \\
\text { neutron } \\
\text { multiplication, } \\
\Sigma M \\
\end{array}$ \\
\hline Base case, void & 0 & 0 & 0 & 0 & 0.95042 & 0.00028 & 20.2 & 0.0 & - \\
\hline HDPE & 1 & 0 & 0 & 0 & 0.95717 & 0.00027 & 23.3 & 3.2 & 3.2 \\
\hline HDPE & 1 & 2 & 0 & 0 & 0.96399 & 0.00032 & 27.8 & 4.4 & 7.6 \\
\hline HDPE & 1 & 2 & 3 & 0 & 0.96744 & 0.00026 & 30.7 & 2.9 & 10.5 \\
\hline HDPE & 1 & 2 & 3 & 4 & 0.97408 & 0.00028 & 38.6 & 7.9 & 18.4 \\
\hline
\end{tabular}


The results indicate an increase in multiplication compared to the base case. An increase in multiplication and $k_{\text {eff }}$ for the addition of moderation to the core indicates that the core is slightly under-moderated. There are competing effects here, as well, including providing reflection to the core interior. The removal of the HDPE would show an immediate drop in core multiplication due to a combination of increasing core leakage (reflector removal) and a reduction in moderating material. The parametric study also indicates that neutron absorption due to the presence of additional hydrogen in the HDPE in the core region is certainly not a significant multiplication effect of the moderation and reflection to the ORSA. Because the multiplication is greater than 20, the experiments must be refined to start with a lower multiplication to ensure that the experimental neutron multiplication is kept below the proposed limit of 20.

\subsubsection{Subcritical Assembly Approach-to-Multiplication Limit Parametric Study: Poison/Neutron Absorption}

Another parametric study was performed to examine the effect of neutron absorbing materials and neutron poisons. This study was conducted to demonstrate the feasibility of the ORSA to illustrate the effect on core multiplication from adding neutron poisons to the ORSA core. This is done by replacing the void regions in the CCR, SR, and FCR holes with aluminum, stainless steel 304 (SS304), and borated polyethylene containing $5 \mathrm{wt}$ \% boron (borated HPDE).

The study examines these materials being placed in the assembly holes to discern the changes in the $k_{\text {eff }}$ and to illustrate the poison effect (parasitic neutron absorption) by replacing the voided holes with these materials. Figure 15 provides a map showing how the ORSA control rod voids are filled with the poison materials. The results are shown in Table 8.

Table 8. Neutron absorber (poison) parametric study results

\begin{tabular}{|c|c|c|c|c|c|c|c|c|c|}
\hline $\begin{array}{c}\text { Neutron } \\
\text { absorbing } \\
\text { material }\end{array}$ & $\mathbf{C R}$ & SR & FCR & SR & $\boldsymbol{k}_{\text {eff }}$ & $\boldsymbol{\sigma}$ & $\begin{array}{c}\text { Calculated } \\
\text { neutron } \\
\text { multiplication, } \\
\text { M }\end{array}$ & $\begin{array}{c}\text { Change in } \\
\text { calculated } \\
\text { multiplication, } \\
\Delta \mathrm{M}\end{array}$ & $\begin{array}{c}\text { Cumulative } \\
\text { change in } \\
\text { neutron } \\
\text { multiplication, } \\
\text { इM } \\
\end{array}$ \\
\hline Base case, void & 0 & 0 & 0 & 0 & 0.95042 & 0.00028 & 20.2 & 0.0 & - \\
\hline $\mathrm{Al}$ & 1 & 0 & 0 & 0 & 0.95196 & 0.00031 & 20.8 & 0.6 & 0.6 \\
\hline $\mathrm{Al}$ & 1 & 2 & 0 & 0 & 0.95336 & 0.00028 & 21.4 & 0.6 & 1.3 \\
\hline $\mathrm{Al}$ & 1 & 2 & 3 & 0 & 0.95404 & 0.00029 & 21.8 & 0.3 & 1.6 \\
\hline $\mathrm{Al}$ & 1 & 2 & 3 & 4 & 0.95655 & 0.00028 & 23.0 & 1.3 & 2.8 \\
\hline Base case, void & 0 & 0 & 0 & 0 & 0.95042 & 0.00028 & 20.2 & 0.0 & - \\
\hline Borated HDPE & 1 & 0 & 0 & 0 & 0.92719 & 0.00029 & 13.7 & -6.4 & -6.4 \\
\hline Borated HDPE & 1 & 2 & 0 & 0 & 0.9044 & 0.00031 & 10.5 & -3.3 & -9.7 \\
\hline Borated HDPE & 1 & 2 & 3 & 0 & 0.88538 & 0.00028 & 8.7 & -1.7 & -11.4 \\
\hline Borated HDPE & 1 & 2 & 3 & 4 & 0.85902 & 0.00027 & 7.1 & -1.6 & -13.1 \\
\hline ss304 & 1 & 0 & 0 & 0 & 0.94352 & 0.00027 & 17.7 & -2.5 & -2.5 \\
\hline ss304 & 1 & 2 & 0 & 0 & 0.93727 & 0.00026 & 15.9 & -1.8 & -4.2 \\
\hline ss304 & 1 & 2 & 3 & 0 & 0.92993 & 0.00026 & 14.3 & -1.7 & -5.9 \\
\hline ss304 & 1 & 2 & 3 & 4 & 0.9223 & 0.00026 & 12.9 & -1.4 & -7.3 \\
\hline
\end{tabular}

The results show that $\mathrm{Al}$ negligibly affects the neutron multiplication, as expected. There is a slight increase in core multiplication $(\sim 1.3)$ due to reflection from the $\mathrm{Al}$ in the holes. It would be an interesting material to contrast due to its low interaction probability with neutrons. The HDPE results are a little more impactful to the neutron multiplication. The AGN-201M control elements (SR, CR, and FCR) are made of fuel and are used to control the reactivity of the assembly. The AGN-201M is designed to be essentially optimally moderated. Adding fuel to the core via control rod addition will increase core reactivity. As designed here, ORSA is slightly under-moderated. The addition of HDPE into the core 
holes increases core multiplication ( 18.4). Adding 5 wt. \% natural boron $\left(80.1\right.$ wt. $\%{ }^{11} \mathrm{~B}$ and 19.9 wt. \% $\left.{ }^{10} \mathrm{~B}\right)$ mixed homogeneously in HDPE increases the presence of neutron absorber $\left({ }^{10} \mathrm{~B}\right)$, which increases neutron losses via parasitic absorption. This experiment illustrates the significant effect of simply adding boron to the system, and it highlights the difference between the effect of adding HDPE $(+18.4)$ and HDPE with boron (-13.1). The boron is assumed to be homogeneously distributed throughout the HDPE. SS304 has a neutron poison effect due to the presence of iron in the steel. SS304 was chosen because the material is relatively inexpensive to use and can serve as an additional material for this experiment. SS304 has a more modest decrease in multiplication (-7.3) compared to HDPE with boron (-13.1). This experiment would be an illustrative exercise for students, as it includes adding both moderation (HDPE) and neutron absorbers to the core. The chosen materials are simple to procure and incorporate into the existing suite of experiments. The students would be required to predict the effect on the core and then determine the actual effect via hands-on experiments and measurements. 


\section{ORNL SITE DEPENDENCIES}

\subsection{SAFETY BASIS AND NCS EVALUATIONS}

ORNL safety basis documentation may need to be updated as a result of the changes in fissile mass $(\sim 620$

$\left.\mathrm{g}{ }^{235} \mathrm{U}\right)$. Many ORNL facilities have a default safety basis allowing up to 500 grams of ${ }^{235} \mathrm{U}$. To implement an NCS program at the facility chosen for this purpose, it may be necessary to either locate this subcritical assembly in a facility where an NCS program is already implemented or where an NCS program can be implemented. To implement and maintain NCS limits, a facility would need to be a Hazard Category 2 nuclear facility [13]. Preliminary discussions to date indicate that ORNL building 7709, the Health Physics Research Reactor building, could be a suitable location for this subcritical assembly. The assembly has low inherent radiation background, no significant fission product inventory from past operations due to low power operations, and subcritical operations would not result in an increase in this background. Final design may consider aluminum plating for the fuel plates to preclude the potential for uranium contamination issues during operations.

NCS evaluations will be required to utilize the subcritical assembly for training purposes. It would be desirable to have at least one AGN-201M core present to allow for some flexibility in operations. Fuel plate handling and storage during operations will require a thorough NCS evaluation to derive needed controls and operating limits to support operations. The ANSI/ANS-8 suite of NCS standards will provide the necessary guidance for handling, storage, and hands-on subcritical assembly operations.

The final design work funded by the NCSP in FY21 for this effort will include details regarding the transfer and transportation of AGN-201M fuel plates from Y-12 to ORNL to prepare for subcritical assembly operations.

\subsection{Subcritical Assembly Requirements}

To conduct hands-on operations with fissionable materials outside reactors, the ANS-8 suite of consensus standards is applicable. In particular, ANSI/ANS-8.1-2014 [1] states the following for all manual operations for handling, storing, or transfer/transportation:

Before a new operation with fissionable material is begun, or before an existing operation is changed, it shall be determined that the entire process will be subcritical under both normal and credible abnormal conditions.

Therefore, to ensure that this requirement is met, a detailed Nuclear Criticality Safety Evaluation must be completed by ORNL NCS staff to ensure that all normal and credible abnormal conditions will remain subcritical. The goals of the parametric studies presented in Section 2 are twofold:

1. Based on assumed configurations and materials (fuel and neutron reflectors), ensure that an effective subcritical training assembly can be constructed and operated.

2. Ensure that the proposed ORSA is safe under all normal and credible abnormal conditions.

For the first goal, it is important that an effective core multiplication can be achieved (multiplication of about 20) for an assumed core configuration based on the available materials. This will illustrate the impact of core changes on the NCS parameters. This was verified in the parametric studies in Section 2 of this report. 
Another standard, ANSI/ANS-1-2000 [12] is applicable for the execution of critical experiments, not subcritical experiments. However, there is good guidance that is applicable to personnel safety while performing the hands-on measurements. As fuel and reflector materials are being added to the assembly, the guidance in ANSI/ANS-1-2000 Sections 3.8 and 3.9 can be applied to ensure that personnel are safe and to emulate an approach to critical configuration, even though the subcritical assembly will be inherently safe — subcritical—under all normal and credible abnormal conditions. Relevant passages from these sections are given below.

ANSI/ANS-1-2000, Section 3.8

Manual operations with fissionable material, such as transfer and storage, shall be performed in accordance with American National Standard for Nuclear Criticality Safety in Operations with Fissionable Material Outside Reactors, ANSI/ANS-8.1-1998.

ANSI/ANS-1-2000, Section 3.9

Manual operations that result in reactivity additions to a critical assembly should be limited to a predicted $k_{\text {eff }}$ of 0.9 (a neutron multiplication of 10) for unknown configurations. Manual operations of known configurations with adequate control and analysis should use a predicted $k_{\text {eff }}$ not to exceed 0.95 (a neutron multiplication of 20). When available, measured multiplication values shall take precedence over computed values.

Based on this prudent guidance from ANSI/ANS-1-2000 and the requirements in ANSI/ANS-82014, this subcritical assembly will be designed as inherently safe, with a maximum multiplication of $20\left(k_{\text {eff }}=0.95\right)$ and with a nominal core multiplication of $10\left(k_{\text {eff }}=0.90\right)$. ORSA procedures will be developed based upon these criteria. In accordance with DOE-STD-1027 [13], the implementation of NCS controls requires a formal, DOE-approved NCS program per DOE O 420.1C [14]. Therefore, the ORSA must be utilized as an ORNL Hazard Category 2 Nuclear Facility. In the next phase of this work, ORNL locations for the ORSA will be studied, scoped, and costed. 


\section{CONCLUSIONS AND RECOMMENDATIONS}

It is feasible to utilize legacy AGN-201M research reactor fuel plates to construct a subcritical assembly for use in the NCSP training and education program to support NCS engineer training and qualification goals. Students from local universities, floor-level operation staff, and others who typically do not attend hands-on courses could benefit from this assembly being available at ORNL. This proposed subcritical assembly would also allow for additional NCS training opportunities for nuclear facilities in the eastern half of the United States.

This study indicates that the proposed ORNL subcritical assembly will support the following experiments and NCS parameters to approach the subcritical limit by:

1. adding fissile mass (fuel plate stacking): mass parameter,

2. decreasing distance between the upper and lower halves of the assembly core (fuel plate separation): interaction parameter,

3. adding moderators to the lower core control rod fuel plate holes: moderation parameter, and

4. adding parasitic neutron absorbers to the lower core control rod fuel plate holes: poisons/absorption parameter.

The proposed ORNL subcritical assembly will provide additional student bandwidth to support NCSP training courses and to provide for some backup capacity in the event that nuclear facility operations are disrupted at SNL or NCERC due to some unforeseen issue. The subcritical assembly will be designed to be inherently safe - subcritical under all normal and credible abnormal conditions. The assembly will be designed specifically for hands-on operations during training courses to illustrate NCS principles. Each experiment will allow the students to take neutron measurements and determine the effect on neutron multiplication as the experimental procedure is executed. Neutron multiplication is related to the $k_{\text {eff }}$ of the system due to the changes in the NCS parameter being examined: mass, interaction, moderation, or neutron absorption.

Future work will involve the development of a final design and cost estimate for the subcritical assembly components, to include:

- A Transportation plan for transporting AGN-201M fuel plates from Y-12 to ORNL

- A safety basis revision plan, to include identifying a viable ORNL location for the assembly

- A plan for the NCS evaluation to support fuel plate storage, handling, and assembly operations

- Design of the critical assembly table/assembly stand with a hydraulic, pneumatic, or manual vertical split table capability

- Integration of a neutron detector into the ORSA design for multiplication measurements

- Design of the neutron reflector(s) for the assembly to be used in the fuel stacking experiments

- Design for aluminum plating of the uranium/polyethylene fuel plates 


\section{REFERENCES}

1. ANSI/ANS-8.1-2014(R2019), "Nuclear Criticality Safety in Operations with Fissionable Materials Outside Reactors," American Nuclear Society (2014).

2. Harms, Gary A., Ronald A. Knief, Allison D. Miller, and John T. Ford, "Current Status of the DOE Nuclear Criticality Safety Program Hands-on Criticality Safety Training Course at Sandia," ANS NCSD 2013 - Criticality Safety in the Modern Era: Raising the Bar, Wilmington, NC, (2013).

3. Harms, Gary A. and David E. Ames, "Titanium and/or Aluminum Rod-Replacement Experiments in Fully-Reflected Water-Moderated Square-Pitched U(6.90) $\mathrm{O}_{2}$ Fuel Rod Lattices with 0.67 Fuel to Water Volume Ratio (0.800 cm Pitch)," International Handbook of Evaluated Criticality Safety Benchmark Experiments, SAND2016-9686R (2016).

4. Bowen, Douglas G., "Status and Deployment of the NCSP Training and Education Courses," 2017 Nuclear Criticality Safety Technical Program Review, Oak Ridge National Laboratory (2017).

5. US Department of Energy/National Nuclear Security Administration Nuclear Criticality Safety Program Training and Education Website, https://ncsp.llnl.gov/training.php (2020).

6. Percher, C., "Module 2: Introduction to Critical Experiment Methods," LLNL-PRES-553410 (2011).

7. Y-12 MC\&A Records for AGN-201M Research Reactor Fuel, Kevin Reynolds, correspondence, Y-12 National Security Complex (2020).

8. Biehl, A. T., R. P. Geckler, S. Kahn, and R. Mainhardt, "Elementary Reactor Experimentation," Aerojet General Nucleonics, October 1957.

9. Bowen, D. G., "Space-Time Kinetics of the AGN-201M Research Reactor at the University of New Mexico," Dissertation, University of New Mexico (2015).

10. Wetzel, L., R. Busch, K. Carpenter, and D. Bowen, "Nondestructive and Supplemental Measurements of the University of New Mexico AGN-201M," ORNL/TM-2019/1410, Oak Ridge National Laboratory (2020).

11. Rearden, B. T. and M. A. Jessee, Eds., "SCALE Code System," ORNL/TM-2005/39, Version 6.2, Oak Ridge National Laboratory, Oak Ridge, TN (2017).

12. ANSI/ANS-1-2000(R2019), "Conduct of Critical Experiments," American Nuclear Society (2019).

13. DOE-STD-1027-2018, "Hazard Categorization of DOE Nuclear Facilities," US Department of Energy (2018).

14. DOE O 420.1C, Change 3, "Facility Safety," US Department of Energy (2012) 


\title{
APPENDIX A. NCSP Proposals for a New Subcritical Assembly for the NCSP
}

Proposal \#1 - Submitted to the NCSP for FY2019 Funding

\author{
Nuclear Criticality Safety Program \\ Proposal Template for FY2019 - FY2023
}

1.0 Technical Program Element: Training and Education (T\&E) (ORNL)

2.0 Title and NCSP Task Manager:

Design of a Subcritical Assembly at ORNL for Use with the CSO/FMH Courses

ORNL NCSP Task Manager and Training and Education Course Coordinator: Douglas G. Bowen

\subsection{Description}

This is a new proposal to develop a subcritical assembly for use in the Nuclear Criticality Safety Program (NCSP) Criticality Safety Officer (CSO) and Fissile Material Handler (FMH) training being designed by the NCSP starting in FY2019. The CSO/FMH task was approved by the NCSP manager in FY2018 but was delayed until FY2019 to allow time for the CSSG to develop the baseline content for the course. The approved CSO/FMH courses included two potential types of courses: a 3-day course and a 5-day course. The 5-day course would include a hands-on component; however, the 3-day course would not, but it could be taught on-site as needed. The inclusion of a subcritical assembly located at Oak Ridge National Laboratory allows the CSO/FMH course to be taught near many sites in the eastern United States with CSOs and FHMs. Many sites will not invest travel and labor costs sending CSOs and FMHs to courses such as these, and this is one way to attract as many CSOs and FMHs to the training course. The subcritical assembly is based on the availability of AGN-201M research reactor cores in storage at Y-12. The AGN-201M core is designed with the smallest ${ }^{235} \mathrm{U}$ content of any research reactor (667 grams of ${ }^{235} \mathrm{U}$ ). The uranium is enriched to less than $20 \mathrm{wt} . \%{ }^{235} \mathrm{U}$, and the uranium is in the form of uranium dioxide distributed in a polyethylene moderator. Scoping calculations indicate that with the reactor-grade graphite-which is used in the research reactor configuration to achieve a delayed and slightly delayed supercritical state (max. power of $\sim 5 \mathrm{~W}$ thermal) - the core can achieve a core multiplication of 20 ( $\left.\mathrm{k}_{\text {eff }}->\right)$ $0.95)$ by controlling the thickness of graphite used. The AGN-201M core is designed with core plates that can be stacked by hand, along with the graphite reflector shell. Therefore, once it is designed and fabricated, this assembly would be similar to the Training Assembly for Criticality Safety (TACS) that is used for the NCSP manager training and the 2-week hands-on courses. A figure of the AGN-201M core is shown in Figure 1. The actual design details will be provided in preliminary and final designs. The AGN critical assembly will be located at an ORNL facility with an active documented safety basis. The HFIR facility may be a good option (Hazard Category 1), as it provides access to safety basis personnel and criticality safety analysts in compliance with ANS- 8 standards. Because the core is uranium with an enrichment of less than $20 \mathrm{wt}$. $\%\left({ }^{235} \mathrm{U}\right.$ mass of 667 grams), the safety basis impacts should be minimal. 


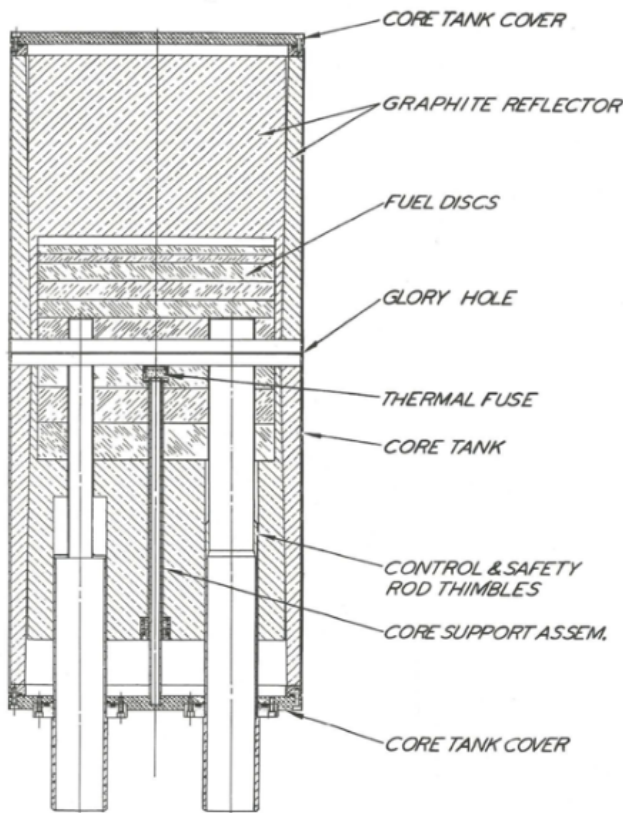

Figure A.1. AGN-201M reactor core detail.

\subsection{Schedule and Budget for Each Year (2019-2023)}

This design work is estimated to be completed in one year.

FY2019 Milestones:

1. Locate AGN-201M core materials at Y-12 (Q1)

2. $\mathrm{Y}-12$ to generate a cost estimate to ship core pieces to ORNL (Q1)

3. Complete core and reflector design and report (Q1)

4. Complete design of the critical assembly platform, detector arrangement, and integration with core/reflector pieces, and associated report (Q3)

5. Determine fabrication (platform and graphite), safety basis, and NCS evaluation cost-based final design details (Q3)

6. Characterize fuel plates and reactor grade graphite to support safety basis and criticality safety support (Q4)

Budget - the numbers below are the current estimates for completion of this project

- FY 2019: ORNL

- FY 2019: Y-12

- Total FY 2019
$\$ 150 \mathrm{~K}$ (includes development and review time) $\$ 50 \mathrm{~K}(\sim 4$ FTE weeks of work) $\$ 200 K$

\subsection{Justification}

This proposal is intended to develop a subcritical assembly based on the AGN-201M reactor core and reflector shell (graphite) that can be used in conjunction with the 5-day CSO/FMH course to be developed starting in FY2019. It has been observed that CSOs and FMH operators are not typically sent to NCS training courses because of the significant travel costs and the number of personnel required to present the training. Locating the subcritical assembly at ORNL will allow those CSO/FMH personnel located on the eastern side of the United States to attend the course more affordably. Of course, the CSO/FMH course 
would still be offered at Sandia and NCERC for those who are able to attend. The other benefit of the proposed location of this assembly is to provide the opportunity for students at nearby universities to attend. ORNL has the advantage of easy access for uncleared and foreign nationals to attend the course. There are currently six weeks of training being conducted at Sandia and NCERC, and the new CSO/FMH training will compete with NCSP and other priorities. An ORNL subcritical assembly will allow training to be conducted without impact to other NCSP priorities at Sandia and NCERC.

\section{Proposal \#2 - Submitted to the NCSP for FY2021 Funding}

\section{Nuclear Criticality Safety Program \\ Proposal Template for FY2021 - FY2025}

\subsection{Technical Program Element: Training and Education (T\&E) (ORNL)}

\subsection{Title and NCSP Task Manager:}

Design of a Subcritical/Critical Assembly at ORNL for Use with the CSO/FMH Courses

ORNL NCSP Task Manager and Training and Education Course Coordinator: Douglas G. Bowen

\subsection{Description}

This is a second proposal to develop a subcritical assembly for use in the Nuclear Criticality Safety Program (NCSP) Criticality Safety Officer (CSO) and Fissile Material Handler (FMH) training being designed by the NCSP starting in FY2019. This is a continuing task based on the results of a feasibility study or preliminary design performed in FY2019. The inclusion of a subcritical assembly located at Oak Ridge National Laboratory allows the CSO/FMH course to be taught in close proximity to many sites in the eastern United States with CSOs and FHMs. Many sites will not invest travel and labor costs to send CSOs and FMHs to NCS courses; this can be a way to attract as many CSOs and FMHs to the training course. Furthermore, this assembly can be used to offset facility issues at either NCERC or Sandia and can be used to train university students in the southeast United States.

AGN-201M research reactor fuel is available at Y-12 (Catholic University, University of Utah, Georgia Tech, Memphis State, University of Oklahoma, and the Naval Post Graduate School). This fuel can easily be shipped to ORNL and stored at an ORNL Hazard Category 1 or 2 nuclear facility. The use of this subcritical assembly at ORNL is possible via the ORNL NCS program and, of course, criticality evaluations will have to be performed to support the work. The feasibility study concluded that $\mathrm{Be}, \mathrm{BeO}$, graphite, SS304, or $\mathrm{Cu}$ can be used as reflectors for this system. The reflectors are to be 3D printed at the ORNL Material Demonstration Facility to the specifications required to achieve the required assembly multiplication.

The AGN-201M core is designed with the smallest ${ }^{235} \mathrm{U}$ content of any research reactor $(667$ grams of ${ }^{235} \mathrm{U}$ ). The uranium is enriched to less than $20 \mathrm{wt} . \%{ }^{235} \mathrm{U}$, and the uranium is in the form of uranium dioxide distributed in a polyethylene moderator. Scoping calculations indicate that with the reactor-grade graphite - which is used in the research reactor configuration to achieve a delayed and slightly delayed supercritical state (max. power of $\sim 5 \mathrm{~W}$ thermal) - the core can achieve a core multiplication of $20\left(k_{\text {eff }}=\right.$ 0.95 ) by controlling the thickness of graphite or other neutron reflector. The feasibility study performed in FY2019 included a parametric study with a variety of reflector types. The AGN-201M core is designed with core plates that can be stacked by hand, so approach-to-critical exercises can be performed. If approved by ORNL, sufficient fuel material exists to perform delayed critical measurements to support high assay LEU benchmarks for the NCS community. 
Like TACs, the final assembly will take up little space in a nuclear facility. The fuel will be stored in accordance with local procedures and NCS limits. It is expected that facility costs will be small.

\subsection{Schedule, Budget, and Milestones}

Cost sharing is being explored with the University of Tennessee, Knoxville and Oak Ridge National Laboratory (3D-printed reflector shells and assembly stand).

\begin{tabular}{lccccc}
\hline ORNL budget & $\mathbf{2 0 2 1}$ & $\mathbf{2 0 2 2}$ & $\mathbf{2 0 2 3}$ & $\mathbf{2 0 2 4}$ & $\mathbf{2 0 2 5}$ \\
\hline $\begin{array}{l}\text { CED-2 equivalent: Finalize design of subcritical assembly } \\
\text { to include assembly stand, detector arrangement, and } \\
\text { reflector shells. }\end{array}$ & $\$ 125 \mathrm{~K}$ & $\$ 0$ & $\$ 0$ & $\$ 0$ & $\$ 0$ \\
$\begin{array}{l}\text { Determine costs to fabricate platform and graphite, as well } \\
\text { as safety basis and nuclear criticality safety evaluation costs } \\
\text { based on final design details. }\end{array}$ & & & & & \\
\hline Total cost & $\mathbf{\$ 1 2 5 K}$ & $\mathbf{\$ 0 K}$ & $\mathbf{\$ 0}$ & $\mathbf{\$ 0}$ & $\mathbf{\$ 0}$ \\
\hline & & & & & \\
& & & & & \\
\hline Y-12 budget & $\mathbf{2 0 2 1}$ & $\mathbf{2 0 2 2}$ & $\mathbf{2 0 2 3}$ & $\mathbf{2 0 2 4}$ & $\mathbf{2 0 2 5}$ \\
\hline $\begin{array}{l}\text { Y-12 to generate a cost estimate to ship core pieces to } \\
\text { ORNL (Q4) }\end{array}$ & $\begin{array}{c}\text { FY19 } \\
\text { funds to } \\
\text { be used }\end{array}$ & $\$ 0$ & $\$ 0$ & $\$ 0$ & $\$ 0$ \\
\hline Total cost & $\mathbf{\$ 0 K}$ & $\mathbf{\$ 0 K}$ & $\mathbf{\$ 0 K}$ & $\mathbf{\$ 0 K}$ & $\mathbf{\$ 0 K}$ \\
\hline
\end{tabular}

\subsection{Justification}

This proposal is intended to be used in conjunction with the 5-day CSO/FMH course that will be piloted in FY2020. It has been observed that CSOs and FMH operators are not typically sent to NCS training courses because of the significant travel costs and the number of personnel required to present the training. Locating the subcritical assembly at ORNL will allow those CSO/FMH personnel located on the eastern side of the United States to attend the course more affordably. Of course, the CSO/FMH course would still be offered at Sandia and NCERC for those who are able to attend. The other benefit of the proposed location of this assembly is to provide the opportunity for students at nearby universities to attend. ORNL has the advantage of easy access for uncleared and foreign nationals to attend the course. There are currently six weeks of training being conducted at Sandia and NCERC, and the new CSO/FMH training will compete with NCSP and other priorities. An ORNL subcritical assembly will allow training to be conducted without impact to other NCSP priorities at Sandia and NCERC or for cases in which there are facility issues that impact course offerings. 


\section{APPENDIX B. Y-12 AGN Fuel Inventory}

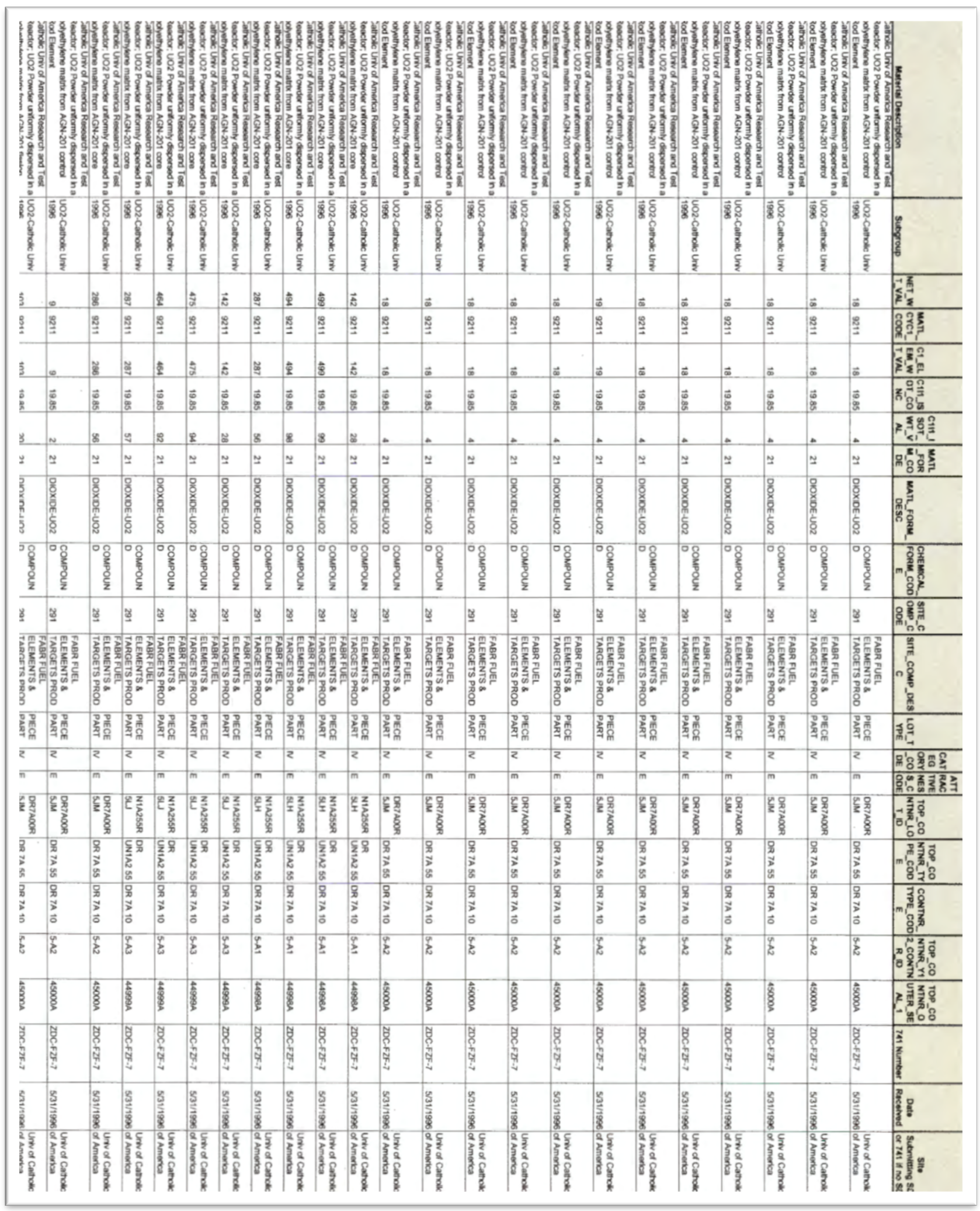

B-31 


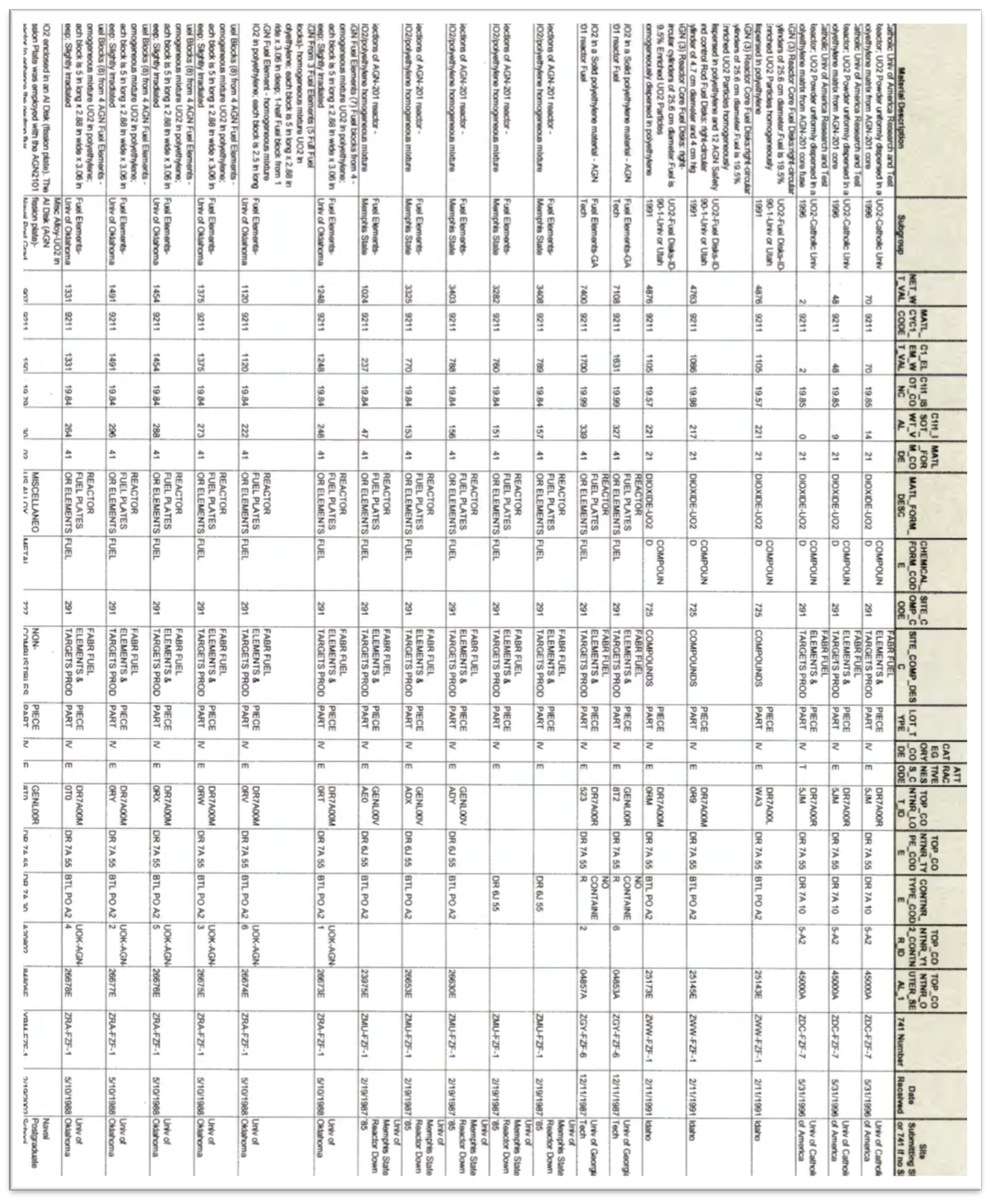

